\title{
I'm not a little kid anymore! Reciprocal social influence in child-adult interaction
}

\author{
Joshua Zonca*1 $^{1}$, Anna Folsø ${ }^{2}$, Alessandra Sciutti ${ }^{1}$
}

1. Cognitive Architecture for Collaborative Technologies (CONTACT) Unit, Italian Institute of Technology, Genoa, Italy.

2. Department of Informatics, Bioengineering, Robotics and Systems Engineering, University of Genoa, Genoa, Italy.

Corresponding author: Correspondence to Joshua Zonca, Italian Institute of Technology, Via Enrico Melen, 83, 16152 Genova, GE (Italy). Email: joshua.zonca@iit.it

Keywords: reciprocity, social influence, development, social norms, conformity

\section{Summary}

Human decisions are often influenced by other's opinions. This process is regulated by social norms: for instance, we tend to reciprocate the consideration received from others, independently of their reliability as information sources. Nonetheless, no study to date has investigated whether and how reciprocity modulates social influence in child-adult interaction. We tested 6,8 and 10 years old children in a novel interactive perceptual task. A child and an adult experimenter made perceptual estimates and then took turns in making a final decision, choosing between own and partner's response. We manipulated the final choices of the adult's partner, who in one condition chose often the child's estimates, whereas in another condition tended to confirm her own response. Results reveal that 10 years old children indeed reciprocated the consideration received from the partner, increasing their level of conformity to the adult's judgments when the partner had shown high consideration towards them. At the same time, 10 years old children employed more elaborate decision criteria in choosing when trusting the adult partner and did not show egocentric biases in their final decisions. Our results shed light on the development of the cognitive and normative mechanisms modulating reciprocal social influence in child-adult interaction. 


\section{Introduction}

Humans often take advice and learn from peers to optimize behavior and decisions. This form of social influence can indeed minimize the cost of individual learning [1-3] and solve uncertainty [4,5]. Crucially, this behavioral practice have allowed humans to accumulate knowledge and transmit culture across generations [6-8]. Several studies have shown that humans can effectively recognize when information provided by peers is reliable and should be used to guide behavior [9-12]. Moreover, they use information about informants' confidence [13,14] and expertise [15-18] to choose the best sources of advice. Importantly, extensive evidence has shown that these abilities are present at an early age in human development. From around 3/4 years of age, children use individual characteristics of adults and peers, including expertise, confidence and age, to select the best informants for learning [19-23]. Moreover, children implement cognitive strategies to select the best informants and the most appropriate circumstances to learn and follow advices in social contexts [24-26].

Nonetheless, sometimes humans use suboptimal informational criteria for social learning and social decision making. One the one hand, this can happen due cognitive biases: for instance, people tend to overdiscount socially acquired information [27-30], over-estimate their own abilities [31,32] and under-estimate own responsibility for undesired outcomes in cooperative settings [33,34]. On the other hand, distortions in the integration of social feedback can occur due to social norms: people tend indeed to conform to their peers to preserve self-image and reputation in their social group [35-38]. In this respect, several studies have shown that biases in judgment and decision making due to normative social influence emerge in earlymiddle childhood [39-41]. Nevertheless, normative conformity tends to increase with age and achieves its peak in early-middle adolescence [42-48]. A pervasive social norm regulating human behavior is reciprocity: we tend to help who has helped us in the past and who could help us in the future. Crucially, reciprocity is considered as one of the key elements sustaining the emergence and the maintenance of cooperation between individuals and within social groups $[49,50]$. Furthermore, reciprocity is known as one of the most important factors sustaining the development of cooperative behavior in childhood. Several studies have indeed shown that children as young as 8-9 years old reciprocate the trust received from a partner in the trust game [51,52]. However, reciprocal behavior becomes more prominent during preadolescence and adolescence [51,53,54]. In this period of human development, reciprocity becomes also more elaborate [55]: for instance, adolescents' willingness to reciprocate is mediated by the risk taken by the partner (i.e., the investor) in the trust game [54,56]. Nonetheless, simpler forms of reciprocity can emerge earlier during childhood. Preschool-age children (5-6 years old) show reciprocity in anticipation to repeated interactions [57], match their own behavior with the one of their counterpart during interaction [53] and reciprocate imitation received from an adult partner [58]. Moreover, preschoolers are able to 
anticipate future reciprocity of their interacting partners: they share more resources with partners who will have the possibility to reciprocate in the future [59] and expect to receive resources from whom have been favored in the past [60]. Children as young as four years of age tend to distribute more resources to rich rather than poor recipients, if the former have shown an intention to reciprocate [61]. 3 years old children selectively show pro-social behaviors towards pro-social partners [62,63], examine the intentions of partners to modulate pro-social behaviors towards them [64,65] and engage in costly punishment [66]. A preference for fair and generous donors has been found even in infants $[67,68]$.

Interestingly, a recent study [69] has shown that reciprocity can modulate social influence and advice taking in adult dyads: people tend indeed to take more into account the opinion of someone who, in turn, show high consideration towards their judgments. These results highlight that reciprocity regulates not only cooperative behavior but also the exchange of information between peers, which does not follow purely Bayesian principle of information aggregation [9]. Nonetheless, no study to date has investigated the developmental features of this phenomenon. In particular, we do not know whether and how children at different stages of development may reciprocate the consideration received from an adult. This aspect is fundamental in the understanding of the process of consolidation of child-adult relationships, especially when they incorporate an educational component, both in domestic (i.e. parent-child relationship) and scholastic (i.e., teacher-student relationship) environments.

In the current study, we investigate whether children of different ages $(6,8$ and 10 years old) engage in reciprocal behavior when making perceptual judgments and exchanging opinions about them with an adult partner. We selected this age range for several reasons. First, this age range is critical in the development of different forms of reciprocity, as already described in the literature review (e.g.,51,52). In fact, reciprocal social influence is a rather subtle and complex type of normative behavior, in which individuals need to take into account several correlated factors, including informational uncertainty and confidence of the interactive partners, as well as the psychological and normative implications of giving and receiving consideration. For this reason, reciprocity in social influence contexts might emerge at an advanced stage of child development. Second, the selected age range is crucial in the emergence and evolution of normative mechanisms of conformity, which is known to become more and more prominent during childhood [39,40,41]. Third, children between 6 and 10 years of age live a crucial phase for the consolidation of childadult relationships, both in scholastic and domestic educational settings. Fourth, including younger children (i.e., preschoolers) in a non-trivial experimental task, as the one described in this study, would have posed several issues in the comparability of results due to differences in terms of attentional focus and performance. In this respect, we highlight that a similar perceptual task has been successfully performed by children from 6 years of age in a previous work [70]. 
We introduce a novel interactive perceptual inference task (Reciprocal social influence task). In each trial, a child and an adult partner made a perceptual estimate and then, in alternated experimental blocks, either the child or the adult took a final decision, choosing between own and other's response. We manipulated the adult's partner response to create two different experimental conditions: Susceptible and Unsusceptible. In the former condition, the adult partner trusted with high probability the opinion of the child; in the latter condition, she tended to not consider the child's opinion and confirmed her own response. We compared children's behavior across conditions to investigate the emergence of reciprocity of social influence at different ages. We also analyzed children's sensitivity to the perceived reliability of social feedback to better understand the role of informational and normative factors in determining age-dependent response profiles.

Results reveal that 10 years old children did engage in reciprocal behavior: they chose more often the partner's estimate in the Susceptible condition, when the adult partner's took into account children's responses. 10 years old children showed also a more elaborate pattern of response in terms of informational consideration: they did not show egocentric bias, which was particularly pronounced in younger children, and adapted their willingness to follow other's opinions based on their perceived reliability. We interpret these findings as an indication that, at 10 years of age, children acquire the ability to integrate informational evaluations, intentions and social norms in an exhaustive representation of the ongoing interaction, leading to a complex behavior that can efficiently balance accuracy of response and appropriateness of behavior in social settings.

\section{Methods}

\section{Participants}

We collected data from 65 children from an elementary school in Genoa (Italy). We tested children of three different classes of different educational levels: $1^{\text {st }}$ grade $(N=21,8$ females, mean age $(M)=6$ years and 4 months, standard deviation $(\mathrm{SD})=3.79$ months), $3^{\text {rd }}$ grade $(\mathrm{N}=21,12$ females, $\mathrm{M}=8$ years and 4 months, $\mathrm{SD}=5.13$ months $), 5^{\text {th }}$ grade $(\mathrm{N}=23,13$ females, $\mathrm{M}=10$ years and 3 months, $\mathrm{SD}=3.09$ months $)$. The target sample size was estimated based on the predicted statistical analyses aimed to detect 1) a significant effect of age on reciprocity, defined as the differences between the influence exerted by the adult partner on children in Susceptible and Unsusceptible conditions and 2) a significant within-subject effect of condition (Susceptible or Unsusceptible) on the influence exerted by adult's partner influence on children in each of the three age cohorts $(6,8,10$ years old). The two analyses are aimed at exploring two different facets of our main experimental hypothesis: the former aims at testing the existence of a linear increase in 
the occurrence of reciprocal behavior along with age, whereas the latter aims at investigating the emergence of reciprocal behavior at a specific step of child development.

Concerning the former analysis, we planned to run a multiple regression analysis with reciprocity as dependent variable and age as continuous independent variable, adjusting for potential confound variables such as performance in perceptual estimation, individual mean social influence and performance ratings. Importantly, to our knowledge there are no previous results showing an effect of age on reciprocal social influence and therefore we do not have any priors about the magnitude of the hypothesized effects. We have therefore assumed a classical medium effect size $\left(\mathrm{f}^{2}=0.15\right)$ along with a two-tailed distribution and a power of 0.8 to obtain the required sample size for a multiple linear regression analysis. The required total sample size resulting from this analysis is 55 .

Concerning the second type of analysis, we have referred to a recent study [69] investigating the emergence of reciprocal social influence in adults. In two experiments, the authors have shown that the adults' willingness to follow the opinion of an (alleged) adult partner was higher when the partner herself had shown high consideration (Susceptible condition) rather than low consideration (Unsusceptible condition) towards them. The effect size of the observed within-subject effect of condition (Susceptible Unsusceptible) was considerably large in both experiments (Exp. 1: $\mathrm{r}=0.57, \mathrm{~d}=1.39$; Exp. 2: $\mathrm{r}=0.46, \mathrm{~d}$ $=1.03$. See the "Statistical data analysis" paragraph for computation of effect sizes). For this reason, we have assumed a medium-to-large effect size $(d=0.6)$ to test the emergence of an effect of reciprocal social influence (i.e., effect of condition) at specific steps of development. Based on these solid previous results, we have also assumed a one-tailed distribution to test a specific directional hypothesis about the emergence of reciprocity in children (i.e., influence in the Susceptible condition higher than influence in the Unsusceptible condition). Given these assumptions, along with an assumed power of 0.8 , the recommended sample size for a Wilcoxon signed-rank test is 20 (See the "Statistical data analysis" paragraph for selection of the statistical methods and tests supporting hypothesis testing). We therefore planned to collect data of at least 20 children for each age cohort, compatibly with the demands of the selected elementary school. This requirement is in line with the requirements of the previous analysis (i.e., a total of 55 participants across age bands).

The study was approved by the local ethics committee and the parents of all participants gave written informed consent prior to testing. All participants had normal or corrected to normal vision acuity.

\section{Reciprocal social influence task: experimental design, procedure and set-up}

The experiment consisted in a partially simulated interaction between a child and an adult experimenter while performing the Reciprocal social influence task (Figure 1). 


\section{a. Experimental task}

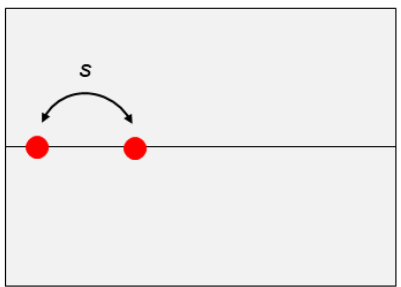

Stimulus presentation

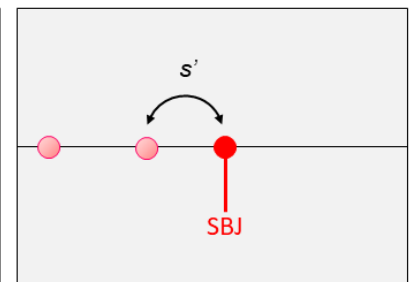

Individual estimate

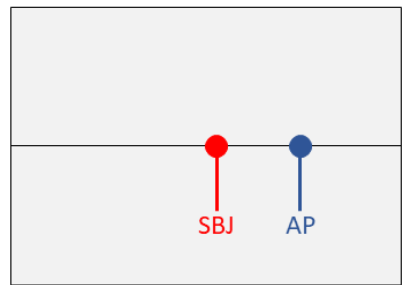

Adult partner's estimate

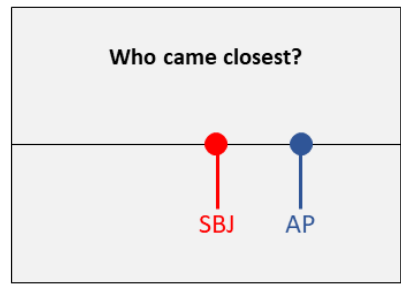

Final decision

\section{b. Experimental design}
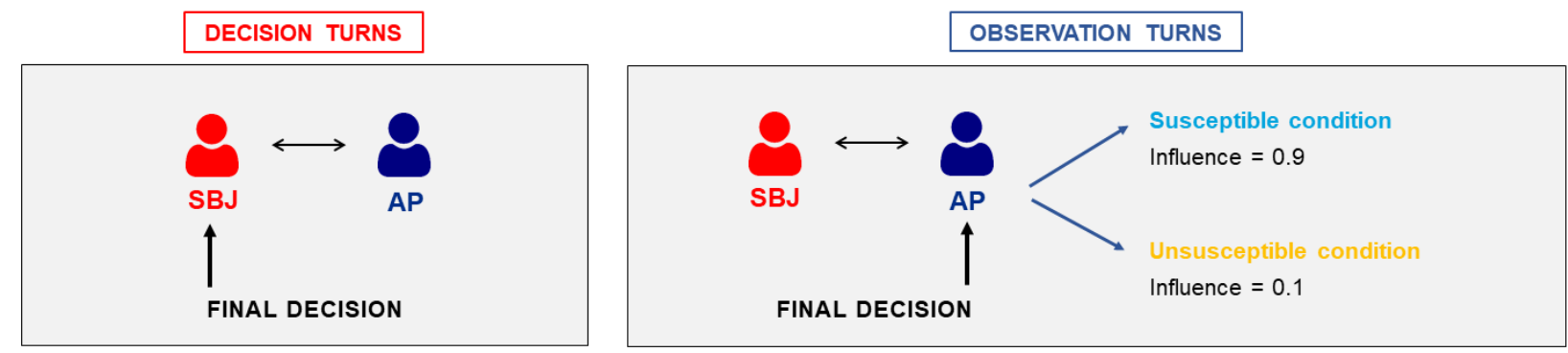

Figure 1. Experimental task and design. a) Experimental task. At the beginning of each trial, participants saw two red disks appearing consecutively on a horizontal line. After their disappearance, participants had to touch a point, to the right of the second disk, in order to reproduce a segment of length ( $\left.s^{\prime}\right)$ that matched the target stimulus length ( $s$, distance between the two red disks). At the same time, an adult partner (i.e., experimenter) saw the same stimuli and simulated the reproduction of the stimulus length s' via mouse click. The estimates of both the participant and the adult partner were shown by red and blue disks underlined respectively by the real name of the child (SBJ) and the real name of the adult partner $(A P)$. Eventually, one of the two agents had the opportunity to make a final decision by choosing either her own or the other agent's response by touching the respective response point (or name) on the screen. Participants could see the final responses of the adult's partner and were aware that the latter could see the participant's final decisions. The final decision, for both agents, was highlighted by a green disk placed in the position of the selected response, which remained visible on the screen for $1 \mathrm{s.b}$ ) Experimental design. In half of the trials (decision turns) the participant herself took the final decision, whereas in the other half of the trials (observation turns) the adult partner took the final decision. In the Susceptible condition, the adult chose the response of the child in 90\% of the cases, whereas in the Unsusceptible condition the adult chose the child's response in 10\% of the trials. In each condition, turns were arranged in blocks of 5 consecutive trials of the same type: first 5 observation turns, then 5 decision turns, and so on, for a total of 20 trials in each condition.

The entire data collection was carried out by the same adult experimenter, who is a woman of 43 years of age, psychotherapist, and external collaborator of the Italian Institute of Technology. During school time, children took turns in following the experimenter in a neighboring room set for the experimental session. 
Children were told that they would have played a game with the experimenter. The experiment lasted approximately 25 minutes, including instructions and break. During the experiment, the experimenter was instructed to maintain a neutral approach while interacting with children during the task. She did not provide neither positive nor negative comments concerning participants' behavior and she did not comment her own responses. In sum, the experimenter did not provide any physical or verbal feedback concerning the two agents' responses. The experimenter was asked to intervene verbally only if participants showed behavior inconsistent with task instructions or were not focused on the task before an experimental trial. Moreover, during the experimental break, she was instructed to ensure that participant were indeed able to continue the experiment.

Participants seated in front of a touch-screen tablet $(27.67 \times 15.56 \mathrm{~cm})$ next to the experimenter (Figure $\mathrm{S} 1$, Supplementary information, Experimental design and set-up). Each trial started with a double tap on the touch-screen from the participant to guarantee that the participant was focused on the task and ready to observe the visual stimuli appearing on the screen. At the beginning of each trial, participants had to reproduce the lengths of visual stimuli that consisted of two consecutive light flashes (red disks of $0.9 \mathrm{~cm}$ diameter, duration $500 \mathrm{~ms}$ ) appearing on a visible horizontal white line crossing the screen at its central height. The first disk appeared at a variable distance from the left border of the screen (min: $0.8 \mathrm{~cm}$, max: $3.5 \mathrm{~cm}$, step: $0.3 \mathrm{~cm}$ ). After the disappearance of the first disk and an inter-stimulus interval of $500 \mathrm{~ms}$, a second disk appeared at a variable distance to the right of the first one.

Participants were asked to reproduce the stimulus length (s), defined as the distance between the first and the second disk, by touching a point on the white line, to the right of the second disk, with their index finger. In each trial, the distance $s$ between the two disks was randomly selected from 11 different sample distances (min: $4.3 \mathrm{~cm}$, max: $9.7 \mathrm{~cm}$, step: $0.6 \mathrm{~cm}$ ). As soon as the children touched the screen, a third red disk marked with a vertical red line and the actual name of the children appeared in the selected position. We did not provide any feedback about the accuracy of the length estimation. Participants were also told that, during this interval, the adult partner would have made her response to estimate the length of the very same stimulus. The experimenter pretended to make her length estimation using a computer mouse. We placed a partition panel between the child and the experimenter to prevent the participant from relying on the amplitude of the movement of the mouse of the experimenter to perform the task. Actually, we implemented a probabilistic algorithm to simulate the perceptual estimates of the adult partner. In each trial, the positions of the adult's perceptual estimate was randomly chosen from a gaussian distribution centered at the correct response $(\mathrm{SD}: 1.06 \mathrm{~cm})$. The standard deviation of the response error distribution was chosen to maintain a balance between variability, credibility and accuracy of response. Moreover, we wanted to always ensure a discrepancy between participant's and adult partner's responses (d). Therefore, whenever the sampled estimate of the algorithm was rather close to the one of the participant (i.e., $\mathrm{d}<0.9 \mathrm{~cm}$ ), the algorithm re- 
sampled a new estimate from the distribution (i.e., until $\mathrm{d} \geq 0.9 \mathrm{~cm}$ ). The choice of this set-up was necessary to have a systematic control of the perceptual estimates of the adult partner to maintain comparability of the adult's performance across experimental conditions and groups.

After $1 \mathrm{~s}$ from the participant's response, the position of adult partner's estimate, marked with a blue vertical line and the name of the experimenter, was shown. Participants knew that also the adult partner was able to see the position of both responses (the one of the children and the one of the adult) on screen. Right after the appearance of the adult's estimate, the final decision phase started. In this phase, one of the two agents (the children or the adult) had the opportunity to make a final decision by selecting either her own or her partner's response. The two agents took the final decisions in different turns. We refer to decision turns as the trials in which the children had to make the final decision, while we refer to observation turns as the trials in which the adult took the final decision. Turns were arranged in blocks of 5 consecutive trials of the same type: first 5 observation turns, then 5 decision turns, and so on.

The experimental manipulation concerned the behavior of the adult partner in terms of final decisions in the observation turns. In the Susceptible condition, the adult chose the response of the children in $90 \%$ of the cases, whereas in the Unsusceptible condition the adult chose the children's response in $10 \%$ of the trials. The sequence of the adult's choices was predetermined (Figure S2, Supplementary Information, Experimental design and set-up): in each condition, the inconsistent choice (i.e., selecting own response in the Susceptible condition, or viceversa) was made during the first block of that condition. We counterbalanced the order of presentation of the Susceptible and the Unsusceptible conditions across participants and within age groups. In sum, participants performed a total of 8 blocks (4 observation and 4 decision turns), divided in two experimental conditions ( 2 observation and 2 decision turns for each condition). In each condition and for each subject, the first block consisted in observation turns. After the first 4 blocks, we introduced a break to allow participants to rest. During the break, the experimenter was instructed to check whether participants were indeed able to continue before re-starting the experiment. Both the children and the adult (i.e., the experimenter) made their final decisions by touching the screen in place of their own or the adult response, or their respective names. At the time of taking the final decision (decision turns), participants could see on the screen the sentence "Who came closest? X (name of the participant) or Y (name of the adult partner)?". During the observation turns, participants could see the sentence "Now Y (name of the adult partner) will choose who came closest, in her opinion". Both agents could see the final responses of the other agent. In particular, participants could see the final responses of the adult's partner and were aware that the latter could see their own final decisions. The final decision of both agents was highlighted by a green disk appearing in the position of the selected perceptual estimate, which remained visible on the screen for $1 \mathrm{~s}$. 
The task was preceded by 4 training trials ( 2 observation trials and 2 decision trials) to allow participants to familiarize with the task. In case participants did not show a full comprehension of the task, we provided additional training trials.

At the end of the task, participants were asked to evaluate from 1 to 10 their own and the adult partner's accuracy in terms of perceptual estimation.

\section{Statistical data analysis}

Most of the analyses reported in this work focus on analysing whether and how exogenous experimental factors (i.e., experimental conditions) and endogenous variables (e.g., participants' age, perceptual error, performance ratings) affected participants' final decisions in the Reciprocal social influence task.

In order to analyze participants' final decisions, we have used mixed-effect logistic models with trial-bytrial final decision (self or partner) as binary dependent variable and random effect at the subject level. Random effects were applied to the intercept to adjust for the baseline level of influence of each subject and model intra-subject correlation of repeated measurements. The variance-covariance matrix of all models was estimated using robust variance estimator [71-73] to obtain heteroscedasticity-robust standard errors clustered at the subject level. All models analyzing trial-by-trial final decisions were also ran adjusting for trial-by-trial potential confounding variables such as perceptual estimation error and agentsresponse distance. These control analyses were ran separately since participants' perceptual estimation error and agents' response distance are highly correlated. Specification and results of each model have been described in detail in the Supplementary information ("Data analysis and results" paragraph).

In the "Results" section of the main text, we report unstandardized regression coefficient $(B), t$ statistic ( $t$ ) and $\mathrm{p}$. value for mixed-effect models and regression analyses. In the Supplementary Information, we report complete fixed-effects results including robust standard errors and confidence intervals. In case of regressions with multiple continuous independent variables, we also report standardized regression coefficients $(\beta)$ for between-predictor comparison.

Furthermore, throughout the paper we also used individual variables to better characterize between-subject behavioral heterogeneity. In this respect, the two most important dependent variables we analysed were: 1) influence, defined as the proportion of trials in which participants chose their partner's estimate in their final decisions and 2) reciprocity, computed as the difference between influence in Susceptible and Unsusceptible conditions for each participant. These dependent variables have been either compared across experimental conditions and groups or analyzed in relation with several predictors including participants' age, perceptual estimation error, agents' response distance and performance ratings. Participant's age (when treated as a continuous variable) was computed as months of age / 12. Participants' perceptual error and agents' response distance were normalized across experimental stimuli dividing their magnitude (in cm) by 
the current stimulus length (in $\mathrm{cm}$ ) to give equal weight to trials including short and long visual stimuli. Ratings were explored by computing the relative difference between rating of own and other's accuracy, to adjust for individual differences in terms of references point within the rating scale (1-10).

Since these individual variables occasionally show some degree of skewness and, in some cases, show a violation of the normality distribution assumption, we used non-parametric tests (i.e., Wilcoxon signedrank test; Wilcoxon rank-sum test) through the entire paper for consistency. All tests are two-tailed (if not specified otherwise) and report $\mathrm{z}$ statistic, $\mathrm{p}$. value and effect sizes $\left(\mathrm{r}, \eta^{2}\right)$. For the same reason, we used non-parametric correlation tests (Spearman's rank correlation). The formulas used for the calculation of the effect sizes can be found in Cohen [74] and Fritz et al. [75]: $r=Z / \sqrt{ } N$ (total number of observations); $\eta^{2}=$ $\mathrm{Z}^{2} / \mathrm{N}$; $\mathrm{d}$ (used in the power analysis for sample size estimation) $=2 \mathrm{r} / \sqrt{ }\left(1-\mathrm{r}^{2}\right)$.

\section{Exclusion of participants}

We aimed to exclude participants who did not comply with the instructions or were not able to remain focused on the task. We therefore analyzed participants' inconsistent responses, which are defined as perceptual inferences spatially located to the left, rather than to the right, of the second of the two disks constituting the reference visual stimulus in the perceptual task. These responses, independently of participants' perceptual accuracy, are by definition incoherent with task instructions, which invite to touch a point to the right of the second disk. We calculated, for each participant, the proportion of inconsistent responses over the total number of trials (40), and we excluded participants whose proportion was two standard deviations above the sample mean (sample mean $=0.03, \mathrm{SD}=0.09$ ). We therefore excluded three participants (6 y/o) whose percentage of inconsistent responses was higher than $21 \%$ of the total number of trials (i.e., more than 8 trials). These participants respectively showed a percentage of $22.5 \%, 37.5 \%$ and $60 \%$ of inconsistent responses. The remaining sample $(\mathrm{N}=62)$ show a very low proportion of inconsistent responses $($ mean $=0.01, \mathrm{SD}=0.03)$, with a maximum of $15 \%$ of inconsistent responses ( 6 trials $)$ in one participant. $77 \%$ of participants did not exhibit any inconsistent responses, while $90 \%$ of participants showed a maximum of one inconsistent response. In sum, all the analyses reported in the current paper include 62 participants ( $6 \mathrm{y} / \mathrm{o}, \mathrm{N}=18 ; 8 \mathrm{y} / \mathrm{o}, \mathrm{N}=21 ; 10 \mathrm{y} / \mathrm{o}, \mathrm{N}=23$ ).

\section{Results}

\section{Social Influence}

First, we analyzed developmental differences in the amount of social influence exerted by the adult partner on children in the Reciprocal social influence task, independently of the experimental condition. We show 
a significant relationship between participants' influence, computed as the proportion of trials in which the child chose the adult's response in her final decisions, and age (linear regression with robust standard errors, standardized coefficient $(\beta)=0.52$, unstandardized coefficient $(B)=0.06, t=4.79, p<0.001)$. This result does not change when adjusting for agents' response distance (effect of age: $\beta=0.52, \mathrm{~B}=0.06, \mathrm{t}=3.80, \mathrm{p}$ $<0.001$; effect of distance: $\beta=-0.01, \mathrm{~B}=-0.01, \mathrm{t}=-0.04, \mathrm{p}=0.967$ ) or participants' estimation error (effect of age: $\beta=0.52, \mathrm{~B}=0.06, \mathrm{t}=3.64, \mathrm{p}=0.001$; effect of error: $\beta=-0.01, \mathrm{~B}=-0.01, \mathrm{t}=-0.05, \mathrm{p}=$ 0.964).

To better characterize the developmental features of social influence, we ran a mixed-effect logistic regression with participant's response (self/other) as dependent variable, age (6-8-10 y/o) as categorical factor and subject as random effect (Supplementary information, Data analysis and results, model 1). Results (Figure 2a) show that 10 years old children were more influenced by the adult partner than 6 years old $(6 \mathrm{y} / \mathrm{o}-10 \mathrm{y} / \mathrm{o}: \mathrm{B}=1.07, \mathrm{z}=4.56, \mathrm{p}<.001)$ and 8 years old children $(8 \mathrm{y} / \mathrm{o}-10 \mathrm{y} / \mathrm{o}: \mathrm{B}=0.64, \mathrm{z}=$ $3.09, \mathrm{p}=.002)$. The difference between 8 and 6 years old children is only marginally significant ( 6 y/o -8 $\mathrm{y} / \mathrm{o}: \mathrm{B}=0.44, \mathrm{z}=1.70, \mathrm{p}=.090)$. We obtain the same effects when adjusting for the distance between the two agents' responses and participants' estimation error in the previous model (Supplementary information, Data analysis and results, model 2,3). In this respect, participants' estimation error in all the three age groups was significantly higher than the one of the adult partner (i.e., computer algorithm) (Wilcoxon signed-rank test. 6 y/o: $\mathrm{z}=-5.12, \mathrm{r}=0.85, \eta^{2}=0.73, \mathrm{p}<0.001 ; 8 \mathrm{y} / \mathrm{o}: \mathrm{z}=-3.91, \mathrm{r}=0.60, \eta^{2}=0.36, \mathrm{p}<$ $0.001 ; 10 y / 0: z=-4.29, r=0.63, \eta^{2}=0.40, p<0.001$. All results are significant at the Bonferroni corrected threshold for 3 comparisons). We also acknowledge that participant's average estimation error was higher in 6 years old children than in the other two age groups ( 6 y/o: Mean \pm std. dev. $=0.62 \pm 0.29 ; 8 \mathrm{y} / \mathrm{o}$ : Mean \pm std. dev. $=0.26 \pm 0.13 ; 10$ y/o: Mean \pm std. dev. $=0.22 \pm 0.06)$. Regression results show that the differences between $6 \mathrm{y} / \mathrm{o}$ children and the other groups are statistically significant $(8 \mathrm{y} / \mathrm{o}-6 \mathrm{y} / \mathrm{o}: \mathrm{B}=-$ $0.29, \mathrm{t}=-4.42, \mathrm{p}<0.001 ; 10 \mathrm{y} / \mathrm{o}-6 \mathrm{y} / \mathrm{o}: \mathrm{B}=0.33, \mathrm{t}=-5.49, \mathrm{p}<0.001)$, whereas there is no difference between 8 and 10 years old participants $(10 \mathrm{y} / \mathrm{o}-8 \mathrm{y} / \mathrm{o}: \mathrm{B}=-0.042, \mathrm{t}=-1.32, \mathrm{p}=0.192)$. However, we did not find any relationship between across-subject variability in individual mean estimation error and between-subject heterogeneity in influence in none of the three age groups. (6 y/o: Spearman correlation, rho $=-0.04, p=0.859 ; 8$ y/o: rho $=0.19, p=0.409 ; 10 \mathrm{y} / \mathrm{o}$ : rho $=-0.14, p=0.522$ ). These results suggest that, at every age level, the general participant's susceptibility to the partner's opinion was not significantly explained by the individual perceptual error. This is not surprising since participants did not receive any feedback about their own and their partner's accuracy along the experiment.

Furthermore, we controlled for potential age-dependent learning effects along the experiment. We divided the experimental task in 4 blocks of 10 trials each to investigate the temporal evolution of participants' estimation error. Results of a mixed-effect model (Supplementary information, Data analysis and results, 
model 4) with estimation error as dependent variable, block, age group and their interaction as independent factors did not reveal any effect of block or interaction between age and block (contrasts of marginal linear predictions, block: $\mathrm{df}=3$, chi2 $=1.44, \mathrm{p}=0.696$; group*block: $\mathrm{df}=6$, chi2 $=3.09, \mathrm{p}=0.797$ ).

Results of performance ratings (Figure $2 b$ ) confirmed than 6 years old children believed to be more accurate than their adult partner (own rating - partner rating: mean $+\mathrm{SD}=2.47 \pm 3.64$; median $=1$. Wilcoxon signed-rank test, $\mathrm{z}=3.09, \mathrm{r}=0.53, \eta^{2}=0.28, \mathrm{p}=0.002$ ) while 8 years old and 10 years old children showed the opposite pattern ( $8 \mathrm{y} / \mathrm{o}$ : $-0.52 \pm 0.87$; median $=0$. Wilcoxon signed-rank test, $\mathrm{z}=-2.39, \mathrm{r}=0.37, \eta^{2}=$ $0.14, \mathrm{p}=0.017 ; 10 \mathrm{y} / \mathrm{o}:-1.23 \pm 1.34$; median $=-1$. Wilcoxon signed-rank test, $\mathrm{z}=-3.79, \mathrm{r}=0.57, \eta^{2}=$ $0.33, \mathrm{p}<0.001$ ). Results of $6 \mathrm{y} / \mathrm{o}$ and $10 \mathrm{y} / \mathrm{o}$ children are significant at Bonferroni-corrected threshold (n. comparisons $=3$ ), while the effect of $8 \mathrm{y} / \mathrm{o}$ children is slightly above the border of Bonferroni-corrected significance threshold (Bonferroni-corrected $\mathrm{p}=0.051$ ). Regression results (own rating - partner rating as dependent variable, age group as dummy factor, robust standard errors) confirm that the differences between the ratings of 6 years old children and the other two participant cohorts are statistically significant $(6 \mathrm{y} / \mathrm{o}-8 \mathrm{y} / \mathrm{o}: \mathrm{B}=2.99, \mathrm{t}=3.33, \mathrm{p}=0.002 ; 6 \mathrm{y} / \mathrm{o}-10 \mathrm{y} / \mathrm{o}: \mathrm{B}=3.70, \mathrm{t}=4.00, \mathrm{p}<0.001)$.

Furthermore, we tested whether children of different age groups modulated trial-by-trial final choices as a function of the current distance between the two agents' responses, which is the only feedback available to participants for extracting information about the relative difference between the two agents' performance. Results of a mixed-effects model (Supplementary information, Data analysis and results, model 5) show that 10 years old children modulated their susceptibility towards the adult partner in function of the current agents' response distance $(\mathrm{B}=0.99, \mathrm{z}=2.17, \mathrm{p}=.030)$, with higher distances leading to a lower probability to follow the partner's advice. Conversely, younger children did not show any relationship between distance and influence ( $6 \mathrm{y} / \mathrm{o}: \mathrm{B}=0.04, \mathrm{z}=0.17, \mathrm{p}=0.863 ; 8 \mathrm{y} / \mathrm{o}: \mathrm{B}=0.27, \mathrm{z}=0.73, \mathrm{p}=0.464$ ).

Taken together, our results show that 10 years old children took much more into consideration the opinion of the adult partner, compared to younger children, in an interactive perceptual inference task. Moreover, 10 years old children were more selective and systematic in choosing when considering the partner's opinion, since they took into consideration the perceived relative accuracy of the two partners to make the final decision. On the contrary, younger children ( 6 and 8 years old) relied significantly less on the adult's advice and did not take into account the relative difference in the accuracy of two agents to take the final decision. 
a.

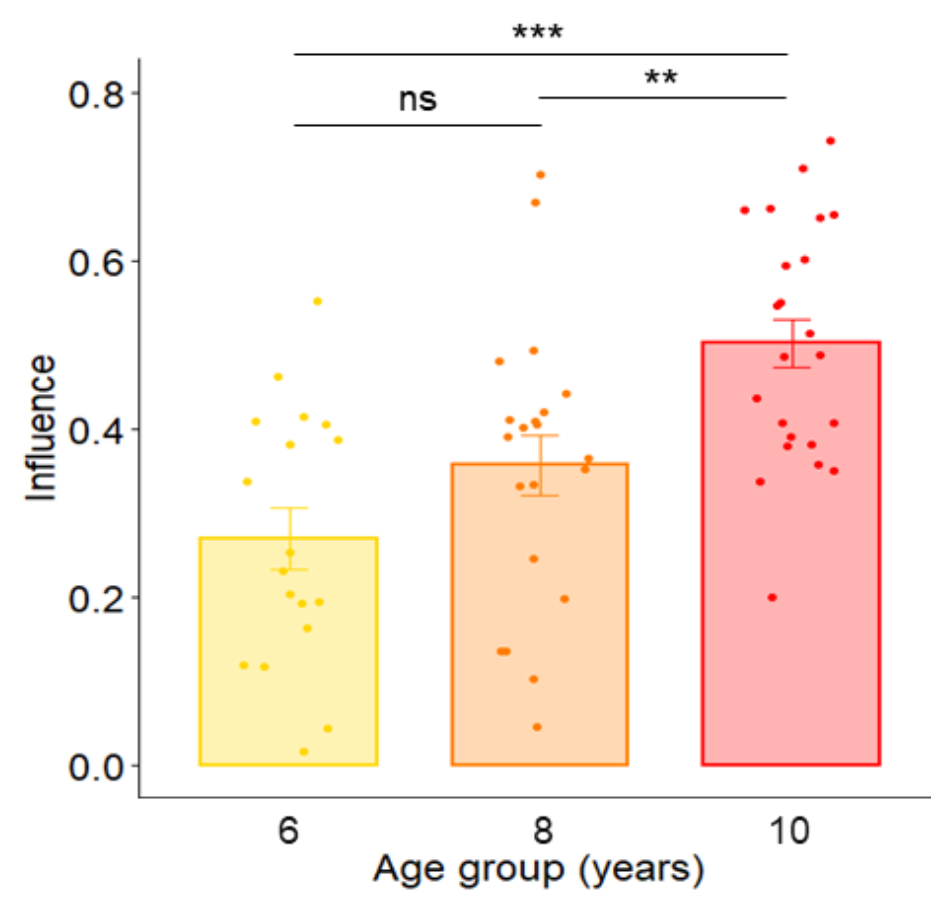

b.

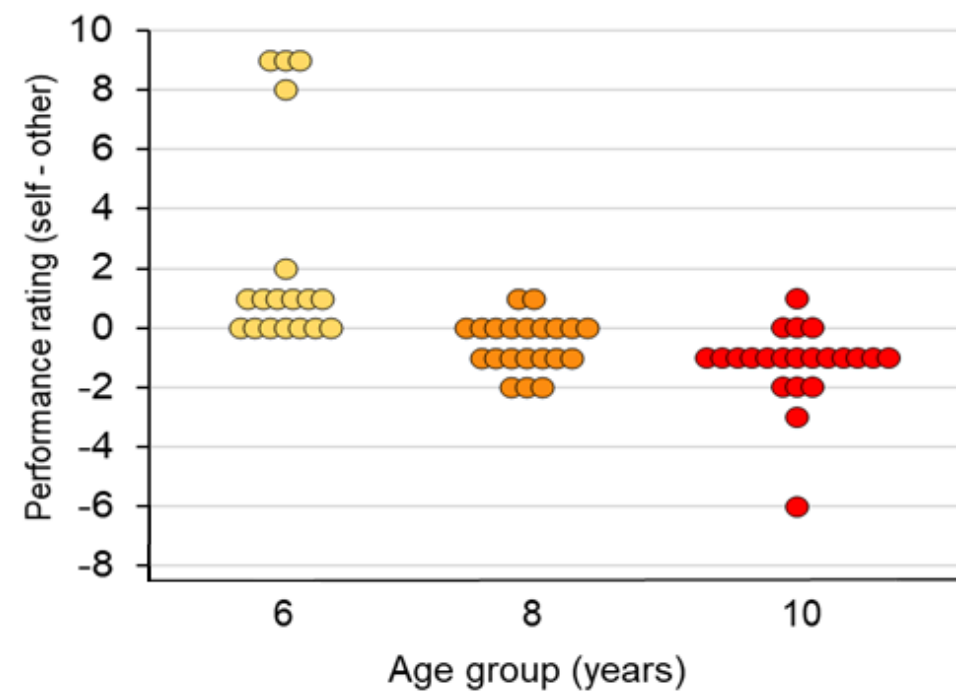

Figure 2. Effect of social influence across age groups. a) Influence exerted by the adult partner on children of different ages $(6,8,10 \mathrm{y} / \mathrm{o})$. Influence is defined as the proportion of decision trials in which the participant chose the estimate of the adult's partner in her final decision. Error bars represent between-subject standard errors of the mean. ** $p<$ $0.01, * * * p<0.001$, ns: not significant. Effect of age group in Mixed-effect model. b) Participants' performance rating (own accuracy rating - adult's partner accuracy rating) across age groups. 


\section{Reciprocity}

Then we analyzed the developmental trajectory of reciprocal social influence. In particular, we tested whether the individual tendency to accept the advice of the adult partner depended on the susceptibility of the adult herself towards the children in the two experimental conditions (Susceptible or Unsusceptible). First, we found than reciprocity, defined as the difference between participants' influence in the Susceptible and the Unsusceptible condition, is significantly predicted by age (multiple linear regression with robust standard errors, $\beta=0.43, \mathrm{~B}=0.04, \mathrm{t}=2.25, \mathrm{p}=0.029$ ), while it is not explained by potential confound variables such as participants' estimation error $(\beta=0.16, \mathrm{~B}=0.12, \mathrm{t}=1.44, \mathrm{p}=0.157)$, average influence $(\beta=-0.27, \mathrm{~B}=-0.24, \mathrm{t}=-1.73, \mathrm{p}=0.089)$ and performance ratings $(\beta=0.13, \mathrm{~B}=0.01, \mathrm{t}=0.81, \mathrm{p}=$ $0.424)$

In order to test whether reciprocal social influence emerges at a specific stage of child development, we also ran a mixed-effect logistic regression (Supplementary information, Data analysis and results, model 6) with participants' final decision as dependent variable, condition (Susceptible or Unsusceptible), age group $(6,8$ and $10 \mathrm{y} / \mathrm{o})$ and their interactions as independent factors, and subject as random effect. Results show a significant effect of condition in 10 years old children $(B=0.31, z=2.86, p=.004)$, who switched more opinion towards the one of the adult partner when the latter has previously shown high consideration towards them (Figure 3a, 3b). This effect was absent in younger children $(6 \mathrm{y} / \mathrm{o}: \mathrm{B}=0.15, \mathrm{z}=0.69, \mathrm{p}$ $=.0 .489 ; 8 \mathrm{y} / \mathrm{o}: \mathrm{B}=0.22, \mathrm{z}=1.18, \mathrm{p}=.0 .239$ ). These findings were confirmed when controlling for agents' response distance and participants' estimation error (Supplementary information, Data analysis and results, model 7,8). In this respect, we highlight that agents' response distance in decision turns was comparable across conditions in all the three age groups (Wilcoxon signed-rank test, $6 \mathrm{y} / \mathrm{o}: \mathrm{z}=0.41, \mathrm{r}=0.07, \eta^{2}=0.00$, $\mathrm{p}=0.679 ; 8 \mathrm{y} / \mathrm{o}: \mathrm{z}=-1.23, \mathrm{r}=0.19, \eta^{2}=0.04, \mathrm{p}=0.217 ; 10 \mathrm{y} / \mathrm{o}: \mathrm{z}=-0.33, \mathrm{r}=0.05, \eta^{2}=0.00, \mathrm{p}=0.738$ ). Similarly, we did not find any between-condition difference in terms of participants' perceptual error in any of the three age groups (Wilcoxon signed-rank test, $6 \mathrm{y} / \mathrm{o}: \mathrm{z}=0.33, \mathrm{r}=0.05, \eta^{2}=0.00, \mathrm{p}=0.744 ; 8$ $\left.\mathrm{y} / \mathrm{o}: \mathrm{z}=-1.75, \mathrm{r}=0.27, \eta^{2}=0.07, \mathrm{p}=0.079 ; 10 \mathrm{y} / \mathrm{o}: \mathrm{z}=-0.33, \mathrm{r}=0.05, \eta^{2}=0.00, \mathrm{p}=0.903\right)$.

Our main effect of reciprocity were corroborated by Wilcoxon signed-rank tests showing that influence was indeed significantly higher in the Susceptible than in the Unsusceptible condition in 10 years old children $\left(\mathrm{z}=2.53, \mathrm{r}=0.37, \eta^{2}=0.14, \mathrm{p}\right.$ (one-tailed) $=0.006$, significant at Bonferroni-corrected threshold, number of comparisons $=3$ ). This effect is absent in 8 years old $\left(z=1.29, r=0.20, \eta^{2}=0.04\right.$, p (one-tailed $\left.)=0.099\right)$ and 6 years old children $\left(z=0.99, r=0.16, \eta^{2}=0.03, p\right.$ (one-tailed) $\left.=0.162\right)$. Altogether, these results reveal that 10 years old children engage in reciprocal behavior in child-adult social influence scenario. 
a.

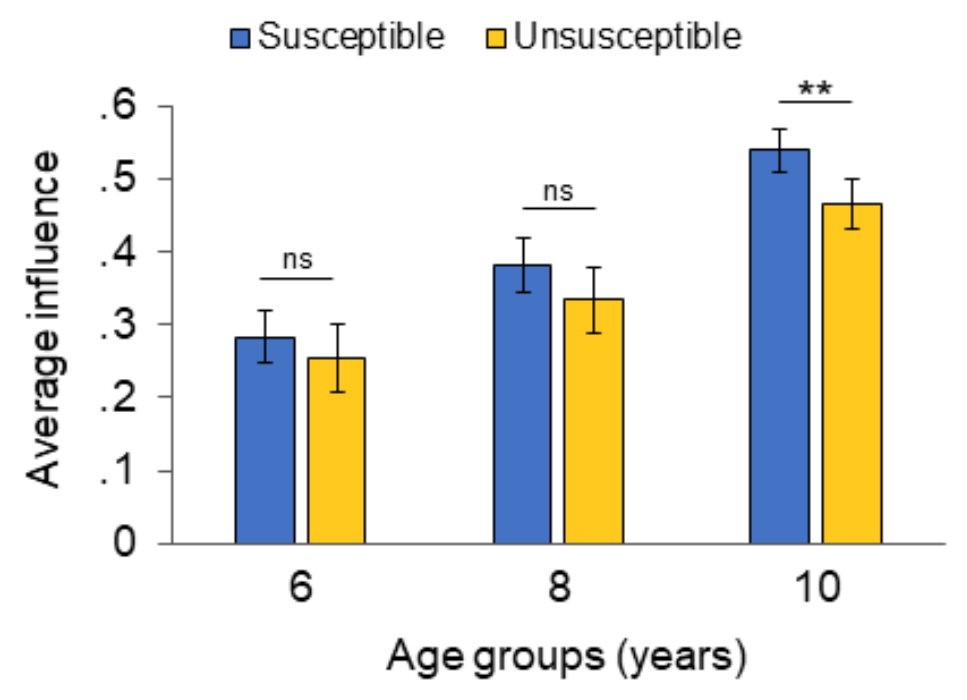

b.

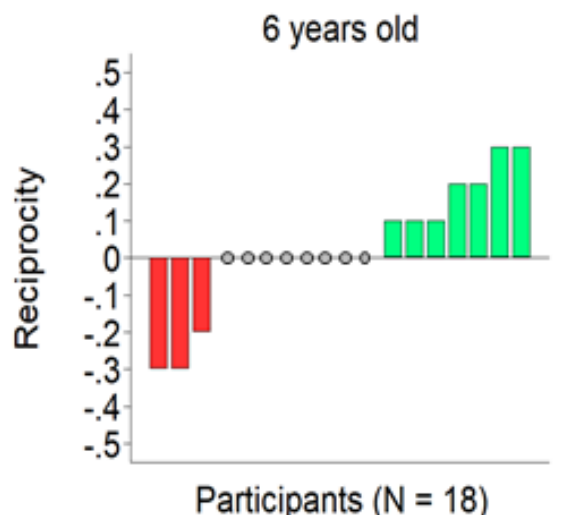

Participants $(\mathrm{N}=18)$
8 years old

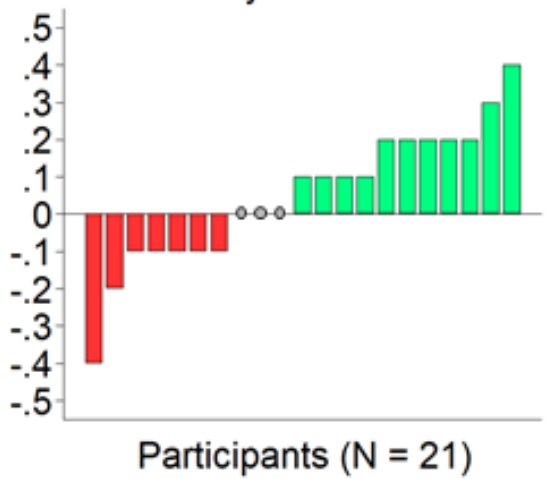

10 years old

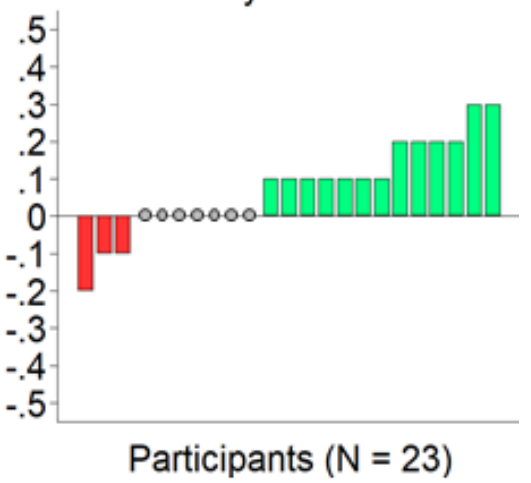

Figure 3. Effect of reciprocity across age groups. a) Average influence in Susceptible and Unsusceptible conditions across age groups $(6,8,10$ y/o). ** $p<0.01$, ns: not significant. Effect of condition by age group in Mixed-effect model. b) Reciprocity index, calculated as influence in the Susceptible condition minus influence in the Insusceptible condition, plotted across participants and divided for age group. Positive values (in green) represent children who showed reciprocal behavior, choosing more often the adult's partner estimate in the decision trials of the Susceptible condition, compared to the Unsusceptible one. Negative values (in red) represent participants who showed antireciprocal behavior and selected less often the partner's estimate in the Susceptible condition. Gray dots represent individuals whose influence was identical across condition. 


\section{Discussion}

Recent evidence [69] has shown that humans engage in reciprocal behavioral when exchanging opinions with another peer. In particular, humans take more into account a partner's opinion when the partner herself has previously shown high consideration towards them, independently of her reliability as informant. However, no study to date investigated the developmental features of reciprocal social influence in childadult interaction. We designed a novel experimental paradigm to investigate the emergence of this phenomenon in 6, 8 and 10 years old children. Participants performed an interactive perceptual task with an adult experimenter. Both agents produced a perceptual estimate of a common visual stimulus, and then took turns making a binary final decision, either choosing to confirm their own response or selecting the partner's estimate. We manipulated the final decisions of the adult partner implementing two different experimental conditions: in the Susceptible condition, the adult partner chose very often the child's estimate, whereas in the Unsusceptible condition she tended to confirm her own estimate. We compared participants' final decisions in the two conditions to explore the emergence of reciprocity in children of different ages. Results indicate that the emergence of reciprocal social influence indeed depends on participants' age. In particular, 10 years children did reciprocated the consideration received from the adult partner, increasing their willingness to choose the partner's opinion in the Susceptible condition. This result held when controlling for informational factors associated with the perception of the two agents' abilities, such as estimation accuracy, agents' response distance and performance ratings. Moreover, the observed emergence of reciprocal behavior is inconsistent with Bayesian principles of information aggregation $[9,69,76]$, which would predict higher participants' susceptibility during an interaction with an unsusceptible partner, since, from an informational point of view, susceptibility can be interpreted as a signal of behavioral uncertainty or incompetence. For these reasons, reciprocal behavior in social influence contexts is generally interpreted as an inherently normative mechanism sustained by the desire to maintain influence over others and avoid the distress of being ignored $[69,77]$.

In contrast, younger children (6 and 8 years old) did not change their final decisions as a function of the partner's behavior. We highlight that these children also showed a lower general susceptibility towards the adult's partner opinion compared to 10 years old participants. More specifically, 10 years old children on average chose the partner's option in about $50 \%$ of the trials, in line with previous results involving preadolescents and adolescents [55]. Conversely, children of 6 and 8 years of age exhibited a considerable egocentric advice discounting [29,30], selecting the partner's estimate only in $27 \%$ and $36 \%$ of the trials, respectively. These findings are consistent with extensive evidence suggesting that normative conformity increases during development, achieving its peak in early-middle adolescence [41-48]. Furthermore, 10 years old participants implemented more sophisticated decision strategies and criteria in their final choices. 
In particular, they took into account the contingent perceived reliability of the partner's estimate, modulating the probability to accept their partner's advice depending on the distance between the two perceptual estimates. On the contrary, younger children did not modulate their susceptibility towards the adult partner based on the perceived reliability of her response, maintaining a more consistent pattern of decisions that favored the confirmation of their own responses and refused the partner's advice.

In sum, we highlight three main findings: 1) 10 years old children reciprocated the consideration received from the partner, increasing their level of susceptibility when the partner had shown high consideration towards them; 2) 10 years old children were generally more influenced by the opinions of an adult partner, compared to 8 and 6 years old children; 3) 10 years old children were more strategic in selecting the circumstances under which following their partner's advice. Taken together, our results suggest that, from the age of 10 , children engage in a richer type of interaction with adults, from both an informational and a normative point of view. An interesting question is whether the ability of implementing sophisticated normative and informational behavior during interaction emerges independently during development or if, alternatively, the application of reciprocation mechanisms is a direct consequence of a more sophisticated type of social interaction. In line with the latter view, several studies have suggested that the implementation of reciprocal behavior in cooperative settings follows the development of specific cognitive mechanisms necessary for engaging in sophisticated interactions. One of these cognitive mechanisms is perspective taking: children reciprocate only when they are able to process and understand exhaustively the goals and intentions of the counterpart $[54,56,78,79]$. Furthermore, reciprocity may require a correct and exhaustive representation of the individual goals, incentives and potential actions of the interacting partners, as well as a full comprehension of the impact of one's choices on the counterpart. In this respect, extensive evidence in social decision making and behavioral economics has shown that these processes require specific cognitive abilities, including first- and second-order mentalizing and cognitive reflection [80-85], which may be underdeveloped in childhood [86-88]. Moreover, in order to engage in reciprocal behavior, children should override selfish impulses in view of a long-term benefit in terms of affiliation and cooperation with peers, an ability that improve during childhood [89-91]. In sum, being able to form a sophisticated representation of the interactive scenario may be necessary to engage in reciprocation in social influence settings. In our experimental task, children need indeed to construct a complex representation of the behavior of the current partner: they must indeed integrate individual motives concerning the attempt to maximize accuracy and, at the same time, the willingness to establish an affiliation with the interacting partners. This interpretation is consistent with result showing that elaborate forms of reciprocity, which take into account the costs and the benefits associated with reciprocal behavior, emerge only at late stages of childhood [51,52] or during pre-adolescence and adolescence [54-56, 92]. 
Nonetheless, in social influence contexts, the emergence of reciprocity requires the possession of specific knowledge about the social norms that regulate advice taking in everyday life. In particular, children should acknowledge that their partner's susceptibility might be influenced by a desire to please them and trust them, and not only by uncertainty or incompetence. It is possible that knowledge about the normative mechanisms modulating advice taking and mutual trust consolidates as a social norm at a late stage of child development, unlike simpler forms of normative behavior (e.g., helping others). We indeed believe the contextual development of both cognitive and social abilities to play a key role in the emergence of reciprocal social influence in childhood.

Eventually, we should acknowledge that our findings shed light on the emergence of reciprocal social influence in a particular type of social interaction, specifically the one occurring between a child and an adult. Child interactions with peers may be indeed regulated by different mechanisms. In fact, we know that conformity in children and adolescents depends on the age of the partners [41,55]. Moreover, the type of social relationship that children establish with adults is inherently different from the one that they establish with other children. In particular, reciprocal behavior may emerge more easily in children who play or collaborate with each other on a regular basis (e.g., friends), rather than in child-adult interactions in which the adult assumes a peculiar educational or authoritarian role (e.g., teacher, parent). Further research should explore the specific mechanisms regulating the interplay between reciprocity and social influence in different types of child-child and child-adult interactions.

Taken together, our results highlight an important component of social influence in childhood, suggesting that children of 10 years of age can engage in reciprocal behavior when exchanging opinions with an adult partner. At this age, children start indeed to react to the consideration they receive from adults and are more willing to take into account the opinion of someone who listens to, rather than ignores, them. We believe these findings to have important implications at the educational level, both in the scholastic and in the domestic domain, opening crucial questions about the efficiency of different educational attitudes towards children and pre-adolescents. 


\section{Ethical statement}

The study was approved by the local ethics committee (Ethical protocol: IIT_HRI) and the parents of all participants gave written informed consent prior to testing.

\section{Funding statement}

The study was funded by internal funds of the Italian Institute of Technology.

\section{Data availability}

The datasets and the codes supporting all the analyses and findings included in the current study, as well as the sources codes used for running the experiment are available to editors and reviewers in a dedicated OSF repository at: https://osf.io/a8s6c/?view only=d911ac19c5e942809f70f834d5247c2f

The entire OSF project will be made publicly available at acceptance.

The datasets supporting the analysis included in this study contain processed, rather than raw, data, following the standards in the field.

\section{Competing interests}

The authors declare no competing interests.

\section{Author contributions}

J.Z., A.S. and A.F. designed the experimental protocol. J.Z and A.F. programmed the experimental tasks. J.Z. and A.F. provided detailed instruction to the experimenter. J.Z. carried out the data analysis and wrote the manuscript. A.S. and A.F. provided suggestions for improving the manuscript. 


\section{References}

1. Laland K. N. (2004). Social learning strategies. Animal Learning \& Behavior, 32(1), 4-14.

2. Morgan, T. J. H., Rendell, L. E., Ehn, M., Hoppitt, W., \& Laland, K. N. (2012). The evolutionary basis of human social learning. Proceedings of the Royal Society B: Biological Sciences, 279(1729), 653-662.

3. Lindström, B., Selbing, I., \& Olsson, A. (2016). Co-evolution of social learning and evolutionary preparedness in dangerous environments. PloS one, 11(8), e0160245.

4. Biele, G., Rieskamp, J., \& Gonzalez, R. (2009). Computational models for the combination of advice and individual learning. Cognitive science, 33(2), 206-242.

5. Kendal, R. L., Coolen, I., \& Laland, K. N. (2004). The role of conformity in foraging when personal and social information conflict. Behavioral Ecology, 15(2), 269-277.

6. Boyd, R., Richerson, P. J., \& Henrich, J. (2011). The cultural niche: Why social learning is essential for human adaptation. Proceedings of the National Academy of Sciences, 108, 10918-10925.

7. Kameda, T., \& Nakanishi, D. (2003). Does social/cultural learning increase human adaptability?: Rogers's question revisited. Evolution and Human Behavior, 24(4), 242-260.

8. Kendal, R. L., Boogert, N. J., Rendell, L., Laland, K. N., Webster, M., \& Jones, P. L. (2018). Social learning strategies: Bridge-building between fields. Trends in cognitive sciences, 22(7), 651-665.

9. De Martino, B., Bobadilla-Suarez, S., Nouguchi, T., Sharot, T., \& Love, B. C. (2017). Social information is integrated into value and confidence judgments according to its reliability. Journal of Neuroscience, 37(25), 6066-6074.

10. Lim, J. S., \& O'Connor, M. (1995). Judgmental adjustment of initial forecasts: its effectiveness and biases. Journal of Behavioral Decision-Making, 8, 149-168.

11. Park, S. A., Goïame, S., O'Connor, D. A., \& Dreher, J. C. (2017). Integration of individual and social information for decision-making in groups of different sizes. PLoS biology, 15(6).

12. Rendell, L., Fogarty, L., Hoppitt, W. J. E., Morgan, T. J. H., Webster, M. M., \& Laland, K. N. (2011). Cognitive culture: Theoretical and empirical insights into social learning strategies. Trends in Cognitive Sciences, 15, 68-76.

13. Bahrami, B., Olsen, K., Latham, P. E., Roepstorff, A., Rees, G., \& Frith, C. D. (2010). Optimally interacting minds. Science, 329(5995), 1081-1085.

14. Sniezek, J. A., \& Van Swol, L. M. (2001). Trust, confidence, and expertise in a judge-advisor system. Organizational Behavior and Human Decision Processes, 84, 288-307.

15. Bonaccio, S., \& Dalal, R. L. (2006). Advice taking and decision-making: An integrative literature review and implications for the organizational sciences. Organizational Behavior and Human Decision Processes, 101, 127-151. 
16. Bonaccio, S., \& Dalal, R. L. (2010). Evaluating advisors: A policy-capturing study under conditions of complete and missing information. Journal of Behavioral Decision Making, 23, 227-249.

17. Boorman, E. D., O’Doherty, J. P., Adolphs, R., \& Rangel, A. (2013). The behavioral and neural mechanisms underlying the tracking of expertise. Neuron, 80(6), 1558-1571.

18. Sniezek, J. A., Schrah, G. E., \& Dalal, R. S. (2004). Improving judgment with prepaid expert advice. Journal of Behavioral Decision Making, 17, 173-190.

19. Jaswal VK, Neely LA. 2006 Adults don't always know best: preschoolers use past reliability over age when learning new words. Psychological Science, 17, 757-758.

20. Koenig, M. A., \& Harris, P. L. (2005a). The role of social cognition in early trust. Trends in Cognitive Sciences, 9(10), 457-459.

21. Koenig, M. A., \& Harris, P. L. (2005b). Preschoolers mistrust ignorant and inaccurate speakers. Child Development, 76(6), 1261-1277. doi:10.1111/j.1467-8624.2005.00849.x

22. Rakoczy, H., Ehrling, C., Harris, P. L., \& Schultze, T. (2015). Young children heed advice selectively. Journal of experimental child psychology, 138, 71-87.

23. Harris, P. L. (2012). Trusting what you're told: How children learn from others. Cambridge, MA: Belknap Press/Harvard University Press.

24. Wood, L. A., Kendal, R. L., \& Flynn, E. G. (2013). Whom do children copy? Model-based biases in social learning. Developmental Review, 33, 341-356.

25. Wood, L. A., Harrison, R. A., Lucas, A. J., McGuigan, N., Burdett, E. R., \& Whiten, A. (2016). "Model age-based" and "copy when uncertain" biases in children's social learning of a novel task. Journal of Experimental Child Psychology, 150, 272-284.

26. Birch, S. A., Vauthier, S. A., \& Bloom, P. (2008). Three-and four-year-olds spontaneously use others' past performance to guide their learning. Cognition, 107(3), 1018-1034.

27. Gardner, P. H., \& Berry, D. C. (1995). The effect of different forms of advice on the control of a simulated complex system. Applied Cognitive Psychology, 9, S55-S79.

28. Toelch, U., Bach, D. R., \& Dolan, R. J. (2014). The neural underpinnings of an optimal exploitation of social information under uncertainty. Social cognitive and affective neuroscience, 9(11), 1746-1753.

29. Yaniv, I. (2004). Receiving other people's advice: Influence and benefit. Organizational Behavior and Human Decision Processes, 13, 1-93.

30. Yaniv, I., \& Kleinberger, E. (2000). Advice taking in decision making: Egocentric discounting and reputation formation. Organizational Behavior and Human Decision Processes, 83, 260-281.

31. Heyes, C. (2012). What's social about social learning?. Journal of Comparative Psychology, 126(2), 193. 
32. Soll, J. B., \& Larrick, R. (2009). Strategies for revising judgment: How (and how well) people use others' opinions. Journal of Experimental Psychology: Learning, Memory, and Cognition, 35, 780-805.

33. Sedikides, C., Campbell, W. K., Reeder, G. D., \& Elliot, A. J. (1998). The self-serving bias in relational context. Journal of Personality and Social Psychology, 74(2), 378.

34. Duval, T. S., \& Silvia, P. J. (2002). Self-awareness, probability of improvement, and the self-serving bias. Journal of personality and social psychology, 82(1), 49.

35. Arndt, J., Schimel, J., Greenberg, J., \& Pyszczynski, T. (2002). The intrinsic self and defensiveness: Evidence that activating the intrinsic self reduces self-handicapping and conformity. Personality and Social Psychology Bulletin, 28(5), 671-683.

36. Asch, S. E. (1951). Effects of group pressure upon the modification and distortion of judgments. Organizational influence processes, 295-303.

37. Cialdini, R. B., \& Goldstein, N. J. (2004). Social influence: Compliance and conformity. Annual Review of Psychology, 55, 591-621.

38. Claidière, N., \& Whiten, A. (2012). Integrating the study of conformity and culture in humans and nonhuman animals. Psychological bulletin, 138(1), 126.

39. Berenda, R. W. The influence of the group on the judgments of children. New York: Kings Crown, 1950.

40. Buritica, J. M. R., Heekeren, H. R., \& van den Bos, W. (2019). The computational basis of following advice in adolescents. Journal of experimental child psychology, 180, 39-54.

41. Large, I., Pellicano, E., Mojzisch, A., \& Krug, K. (2019). Developmental trajectory of social influence integration into perceptual decisions in children. Proceedings of the National Academy of Sciences, 116(7), 2713-2722.

42. Iscoe I, Williams M, Harvey J (1963). Modification of children's judgments by a simulated group technique: A normative developmental study. Child Development, 34:963-978.

43. Hamm NH, Hoving KL (1969). Conformity of children in an ambiguous perceptual situation Child Development, 40:773-784.

44. Costanzo, P. R., \& Shaw, M. E. (1966). Conformity as a function of age level. Child Development, 37, 967-975.

45. Berndt, T. J. (1979). Lack of acceptance of reciprocity norms in preschool children. Developmental Psychology, 15, 662-663.

46. Blakemore S-J, Mills KL. (2014). Is adolescence a sensitive period for sociocultural processing? Annual Review of Psychology 65, 187-207. 
47. Jones, R. M., Somerville, L. H., Li, J., Ruberry, E. J., Powers, A., Mehta, N., ... Casey, B. J. (2014). Adolescent-specific patterns of behavior and neural activity during social reinforcement learning. Cognitive, Affective, \& Behavioral Neuroscience, 14, 683-697.

48. van Hoorn, J., van Dijk, E., Meuwese, R., Rieffe, C., \& Crone, E. A. (2016). Peer influence on prosocial behavior in adolescence. Journal of Research on Adolescence, 26, 90-100.

49. Nowak, M. A. \& Sigmund, K. (1998). Evolution of indirect reciprocity by image scoring. Nature, 393, 573-577.

50. Pfeiffer, T., Rutte, C., Killingback, T., Taborsky, M., \& Bonhoeffer, S. (2005). Evolution of cooperation by generalized reciprocity. Proceedings of the Royal Society B: Biological Sciences, 272(1568), 11151120 .

51. Sutter, M., \& Kocher, M. G. (2007). Trust and trustworthiness across different age groups. Games and Economic behavior, 59(2), 364-382.

52. Güroğlu, B., van den Bos, W., \& Crone, E. A. (2014). Sharing and giving across adolescence: an experimental study examining the development of prosocial behavior. Frontiers in Psychology, 5, 291.

53. House, B., Henrich, J., Sarnecka, B., \& Silk, J. B. (2013). The development of contingent reciprocity in children. Evolution and Human Behavior, 34(2), 86-93.

54. van den Bos, W., Westenberg, M., van Dijk, E., \& Crone, E. A. (2010). Development of trust and reciprocity in adolescence. Cognitive Development, 25(1), 90-102.

55. Molleman, L., Kanngiesser, P., \& van den Bos, W. (2019). Social information use in adolescents: The impact of adults, peers and household composition. PloS one, 14(11), e0225498.

56. van den Bos, W., van Dijk, E., Westenberg, M., Rombouts, S. A., \& Crone, E. A. (2011). Changing brains, changing perspectives: the neurocognitive development of reciprocity. Psychological science, 22(1), 60-70.

57. Sebastián-Enesco, C., \& Warneken, F. (2015). The shadow of the future: 5-year-olds, but not 3-yearolds, adjust their sharing in anticipation of reciprocation. Journal of experimental child psychology, 129, $40-54$.

58. Over, H., Carpenter, M., Spears, R., \& Gattis, M. (2013). Children selectively trust individuals who have imitated them. Social Development, 22(2), 215-224.

59. Xiong, M., Shi, J., Wu, Z., \& Zhang, Z. (2016). Five-year-old preschoolers' sharing is influenced by anticipated reciprocation. Frontiers in psychology, 7, 460.7

60. Paulus, M. (2016). It's payback time: Preschoolers selectively request resources from someone they had benefitted. Developmental psychology, 52(8), 1299.

61. Kenward, B., Hellmer, K., Winter, L.S. \& Eriksson, M. (2015). Four-year-olds' strategic allocation of resources: attempts to elicit reciprocation correlate negatively with spontaneous helping. Cognition, 136, 1-8 
62. Vaish, A., Hepach, R., \& Tomasello, M. (2018). The specificity of reciprocity: Young children reciprocate more generously to those who intentionally benefit them. Journal of Experimental Child Psychology, 167, 336-353.

63. Warneken, F., \& Tomasello, M. (2013). The emergence of contingent reciprocity in young children. Journal of experimental child psychology, 116(2), 338-350.

64. Vaish, A., Carpenter, M., \& Tomasello, M. (2010). Young children selectively avoid helping people with harmful intentions. Child development, 81(6), 1661-1669.

65. Vogelsang, M., \& Tomasello, M. (2016). Giving is nicer than taking: Preschoolers reciprocate based on the social intentions of the distributor. PLoS One, 11(1), e0147539.

66. Robbins, E., \& Rochat, P. (2011). Emerging signs of strong reciprocity in human ontogeny. Frontiers in psychology, 2, 353.

67. Dunfield, K. A., \& Kuhlmeier, V. A. (2010). Intention-mediated selective helping in infancy. Psychological science, 21(4), 523-527.

68. Meristo, M., \& Surian, L. (2013). Do infants detect indirect reciprocity?. Cognition, 129(1), 102-113.

69. Mahmoodi, A., Bahrami, B., \& Mehring, C. (2018). Reciprocity of social influence. Nature communications, 9(1), 1-9.

70. Sciutti, A., Burr, D., Saracco, A., Sandini, G., \& Gori, M. (2014). Development of context dependency in human space perception. Experimental Brain Research, 232(12), 3965-3976.

71. Eicker, F. (1963). Asymptotic normality and consistency of the least squares estimators for families of linear regressions. The Annals of Mathematical Statistics, 447-456.

72. Huber, P. J. (1967, June). The behavior of maximum likelihood estimates under nonstandard conditions. In Proceedings of the fifth Berkeley symposium on mathematical statistics and probability (Vol. 1, No. 1, pp. 221-233).

73. White, H. (1980). A heteroskedasticity-consistent covariance matrix estimator and a direct test for heteroskedasticity. Econometrica: journal of the Econometric Society, 817-838.

74. Cohen, B. (2008). Explaining psychological statistics (3rd ed.). New York: John Wiley \& Sons.

75. Fritz, C. O., Morris, P. E., \& Richler, J. J. (2012). Effect size estimates: current use, calculations, and interpretation. Journal of experimental psychology: General, 141(1), 2.

76. Behrens, T. E., Hunt, L. T., Woolrich, M. W., \& Rushworth, M. F. (2008). Associative learning of social value. Nature, 456, 245-249.

77. Eisenberger, N. I., Lieberman, M. D., \& Williams, K. D. (2003). Does rejection hurt? An fMRI study of social exclusion. Science, 302, 290-292. 
78. Malhotra, D. (2004). Trust and reciprocity decisions: The differing perspectives of trustors and trusted parties. Organizational Behavior and Human Decision Processes, 94(2), 61-73.

79. Schug, J., Takagishi, H., Benech, C., \& Okada, H. (2016). The development of theory of mind and positive and negative reciprocity in preschool children. Frontiers in Psychology, 7, 888.

80. Bilancini, E., Boncinelli, L., \& Mattiassi, A. (2018). Assessing Actual Strategic Behavior to Construct a Measure of Strategic Ability. Frontiers in psychology, 9, 2750.

81. Brañas-Garza, P., Garcia-Muñoz, T., \& González, R. H. (2012). Cognitive effort in the beauty contest game. Journal of Economic Behavior \& Organization, 83(2), 254-260.

82. Carpenter, J., Graham, M., \& Wolf, J. (2013). Cognitive ability and strategic sophistication. Games and Economic Behavior, 80, 115-130.

83. Devetag, G., \& Warglien, M. (2008). Playing the wrong game: An experimental analysis of relational complexity and strategic misrepresentation. Games and Economic Behavior, 62(2), 364-382.

84. Fehr, D., \& Huck, S. (2016). Who knows it is a game? On strategic awareness and cognitive ability. Experimental Economics, 19(4), 713-726.

85. Zonca J., Coricelli, G., \& Polonio, L. (2020). Gaze patterns disclose the link between cognitive reflection and sophistication in strategic interaction. Judgment and Decision Making, 15(2), 230-245.

86. Flobbe, L., Verbrugge, R., Hendriks, P., \& Krämer, I. (2008). Children's application of theory of mind in reasoning and language. Journal of Logic, Language and Information, 17(4), 417-442.

87. Toplak, M. E., West, R. F., \& Stanovich, K. E. (2014). Rational thinking and cognitive sophistication: Development, cognitive abilities, and thinking dispositions. Developmental psychology, 50(4), 1037.

88. Imuta, K., Henry, J. D., Slaughter, V., Selcuk, B., \& Ruffman, T. (2016). Theory of mind and prosocial behavior in childhood: a meta-analytic review. Developmental psychology, 52(8), 1192.

89. Imuta, K., Hayne, H., \& Scarf, D. (2014). I want it all and I want it now: Delay of gratification in preschool children. Developmental psychobiology, 56(7), 1541-1552.

90. Leimgruber, K. L. (2018). The developmental emergence of direct reciprocity and its influence on prosocial behavior. Current Opinion in Psychology, 20, 122-126.

91. Moore, C., Barresi, J., \& Thompson, C. (1998). The cognitive basis of future-oriented prosocial behavior. Social Development, 7(2), 198-218.

92. van de Groep, S., Meuwese, R., Zanolie, K., Güroğlu, B., \& Crone, E. A. (2020). Developmental changes and individual differences in trust and reciprocity in adolescence. Journal of Research on Adolescence, 30, 192-208. 


\section{Supplementary information}

\section{Experimental design and set-up}

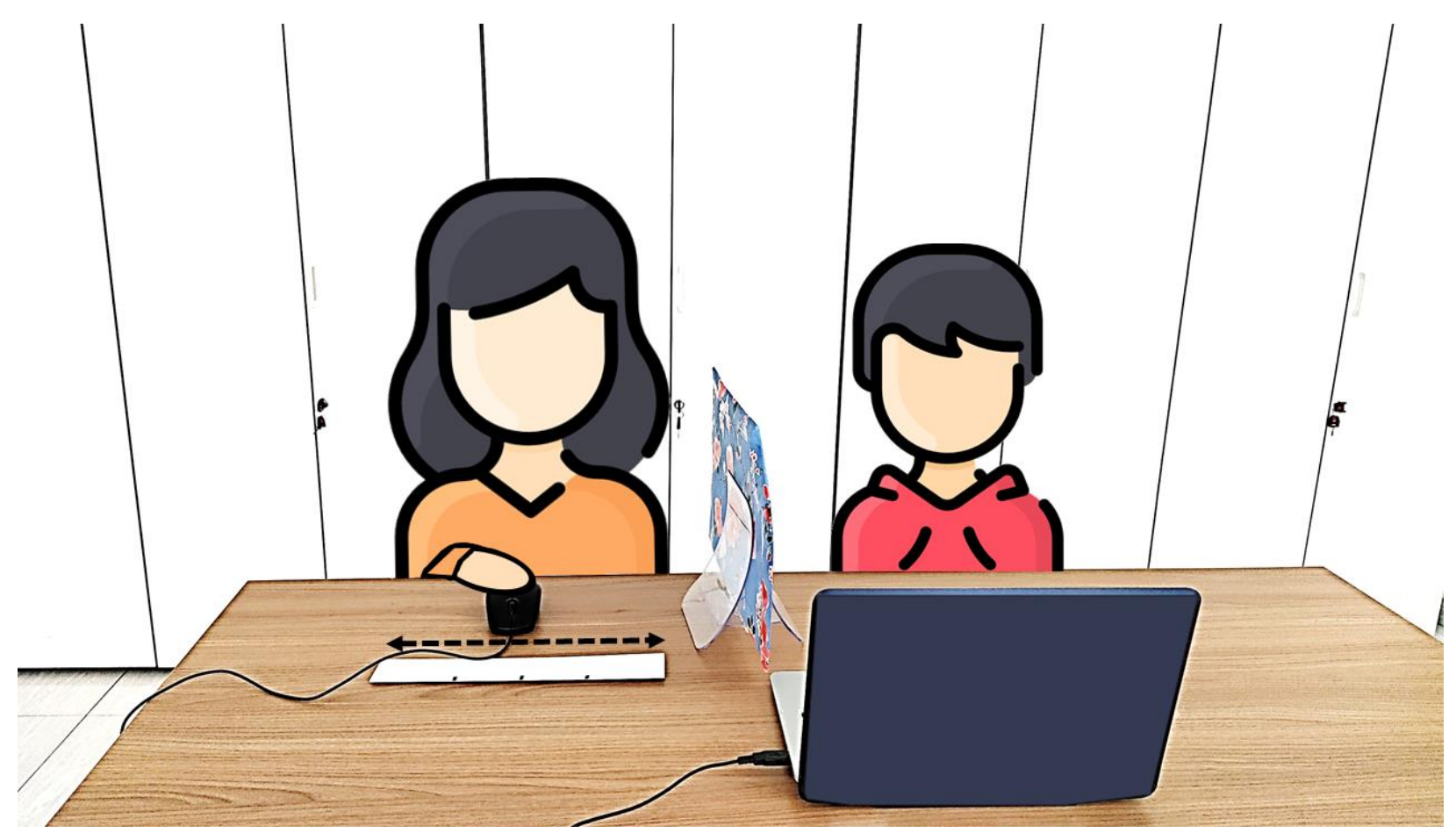

Figure S1. Set-up of the Reciprocal social influence task. Participants seated next to the experimenter (i.e., adult partner in the task), in front of a touch-screen tablet. Participants made their perceptual estimates touching the screen, while the adult partner pretended to make her perceptual estimates using a computer mouse, moving it on the horizontal plane and selecting the response position via mouse click. A partition panel was placed between the participant and the experimenter to prevent the participant from relying on the amplitude of the movement of the adult partner's mouse movement to perform the task. Both the participant and the adult partner made their final decisions by touching the screen in the location of the selected response. Both participants could see the entire screen and knew that the partner could see it as well. Participants could see both perceptual estimates and final decision of the adult partner, and knew that the adult partner could see both participants' perceptual estimates and final responses.

Each trial started with a double tap on the touch-screen by the participant, to ensure that the participant herself was focused on the task and ready to observe the visual stimuli appearing on the screen. 


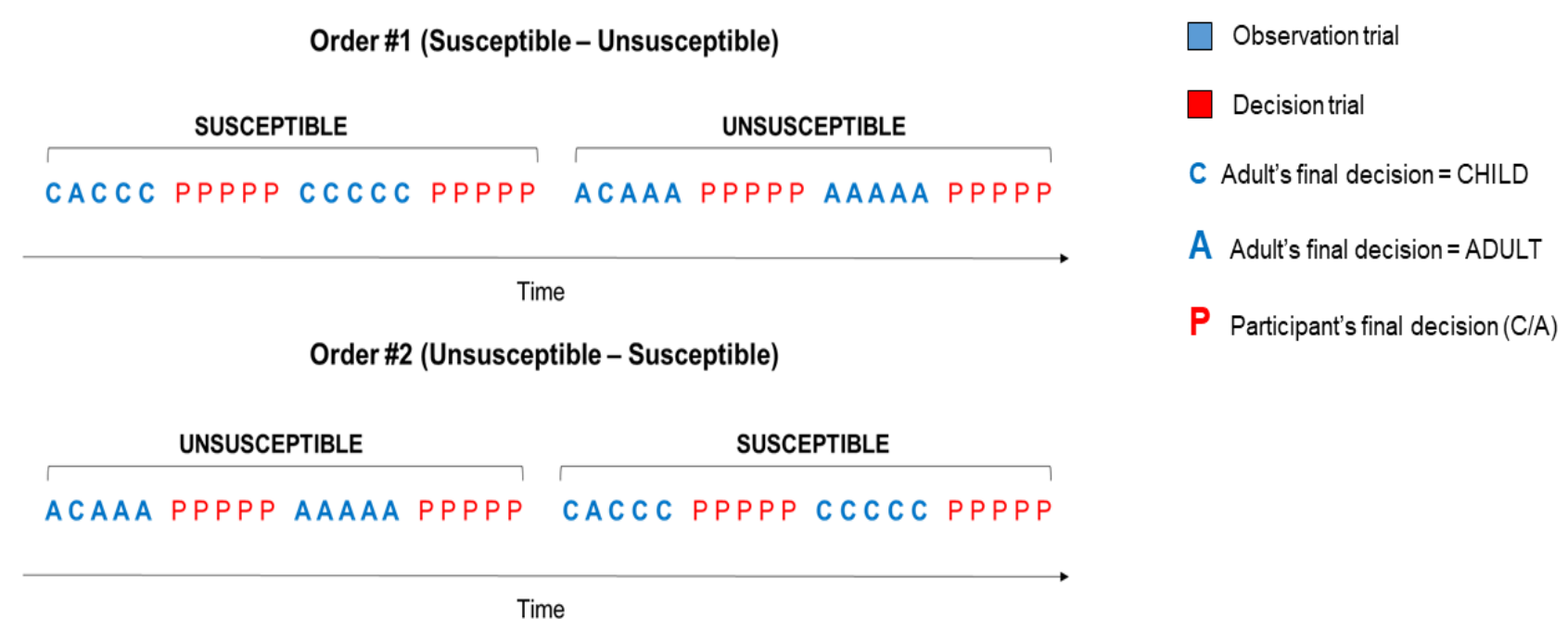

Figure S2. Schematic representation of the temporal evolution of the Reciprocal social influence task. Participants performed 40 trials in total. Half of the trials were observation turns (in blue), in which the adult partner took the final decision. In the remaining half of the trials (decision turns, in red), the participant made the final decision. Observation and decision turns were arranged in mini-blocks of five consecutive trials. Moreover, trials were organized in two different experimental conditions (Susceptible and Unsusceptible) following a within-subject block design. Half of the participants (in each age group) started with the Susceptible condition (order \#1), whereas the other half of the participants started with the Unsusceptible condition (order \#2). In the Susceptible condition, the adult partner, in the observation turns, chose the child's estimate 90\% of the times (9/10); conversely, in the Unsusceptible condition chose the child's response 10\% of the times (1/10). As a general rule, the inconsistent response (e.g., choosing the adult's estimate in the Susceptible condition), occurred in the second (observation) trial of the current condition. 


\section{Data analysis and results}

We report the details of the mixed-effect models ran in the present work. For all models, the intercept was allowed to vary across participants including a random effect at subject level. We estimated the variancecovariance matrix of all models using robust variance estimator to obtain heteroscedasticity-robust stand errors clustered at the subject level.

In every model equation, $\beta$ expresses coefficients of fixed effects, while $u$ indicates random effects.

In the fixed-effect results, B express unstandardized regression coefficients.

\section{Social influence}

\section{$\underline{\text { Effect of age group on final decision }}$}

We tested the effect of age group (dummy variable) on participants' final decision in decision turns. In this analysis we considered all decision trials, independently of the experimental condition. We estimated the following mixed-effect logistic model:

$$
F=\beta_{0}+\beta_{1} a g e+u_{0}+\varepsilon
$$

$F$ is the participant's final binary decision ( 1 = own estimate, $0=$ partner's estimate), and age is a dummy variable corresponding to the three age groups $(6,8$ and $10 \mathrm{y} / \mathrm{o})$. Number of observations $=1240$; number of clusters $=62$.

Results show that 10 years old children were more influenced by the adult partner than 6 years old (6 y/o $10 \mathrm{y} / \mathrm{o}: \mathrm{B}=1.07$, robust $\mathrm{SE}=0.235, \mathrm{z}=4.56, \mathrm{p}<.001,95 \% \mathrm{CI}=[0.612,1.533])$ and 8 years old children $(6 \mathrm{y} / \mathrm{o}-10 \mathrm{y} / \mathrm{o}: \mathrm{B}=0.64$, robust $\mathrm{SE}=0.206, \mathrm{z}=3.09, \mathrm{p}=.002,95 \% \mathrm{CI}=[0.232,1.039])$. The difference between 6 and 8 years old children is only marginally significant (linear combination of coefficients, 6 y/o -8 y/o: $\mathrm{B}=0.44$, robust $\mathrm{SE}=0.258, \mathrm{z}=1.70, \mathrm{p}=.090,95 \% \mathrm{CI}=[-0.068,0.942])$.

\section{Effect of age group on final decision, controlling for agents' response distance}

We added a control variable to the previous model (1) to adjust for the variability captured by agents' response distance. This trial-by-trial measure has been computed has the distance $(\mathrm{cm})$ between the two agents' response divided by the current stimulus length $(\mathrm{cm})$, to normalize for the magnitude of perceptual error based on stimulus length. We used the following mixed-effect logistic model:

$$
F=\beta_{0}+\beta_{1} a g e+\beta_{2} d+u_{0}+\varepsilon
$$


$F$ is the participant's final binary decision $(1=$ own estimate, $0=$ partner's estimate $)$, age is a dummy variable corresponding to the three age groups $(6,8$ and $10 \mathrm{y} / \mathrm{o})$ and $d$ refers to normalized agents' response distance. Number of observations $=1240$; number of clusters $=62$.

Results indicate that the age effect of model (1) do not change when adjusting for normalized agents' response distance. 10 years old children were more influenced by the adult partner than 6 years old (6 y/o $-10 \mathrm{y} / \mathrm{o}: \mathrm{B}=1.01$, robust $\mathrm{SE}=0.255, \mathrm{z}=3.98, \mathrm{p}<.001,95 \% \mathrm{CI}=[0.514,1.513])$ and 8 years old children $(8 \mathrm{y} / \mathrm{o}-10 \mathrm{y} / \mathrm{o}: \mathrm{B}=0.63$, robust $\mathrm{SE}=0.207, \mathrm{z}=3.05, \mathrm{p}=.002,95 \% \mathrm{CI}=[0.226,1.037])$. The difference between 6 and 8 years old children is not significant (linear combination of coefficients, 6 y/o -8 y/o: $\mathrm{B}=$ 0.38 , robust $\mathrm{SE}=0.273, \mathrm{z}=1.40, \mathrm{p}=.162,95 \% \mathrm{CI}=[-0.154,0.918])$. The effect of normalized distance on final decision is not significant $(\mathrm{B}=0.21$, robust $\mathrm{SE}=0.210, \mathrm{z}=1.02, \mathrm{p}=.310,95 \% \mathrm{CI}=[-0.339$, $0.188])$.

We also tested whether between-subject variability in mean normalized agents' response distance explained between-subject heterogeneity in influence, defined as the proportion of final decision towards the estimate of the adult partner, within each age group. We did not find any correlation between the two variables in none of the three age groups (6 y/o: Spearman correlation, rho $=-0.07, \mathrm{p}=0.779 ; 8 \mathrm{y} / \mathrm{o}$ : Spearman correlation, rho $=0.30, \mathrm{p}=0.187 ; 10 \mathrm{y} / \mathrm{o}$ : Spearman correlation, rho $=-0.07, \mathrm{p}=0.758)$. These results indicate that, at every age level, the individual average distance between the two agents' response did not play a key role in determining the general participant's willingness to follow the adult partner's advice. Nonetheless, we acknowledge that 6 y/o children show a higher average normalized agents' response distance compared to the other two age groups ( $6 \mathrm{y} / \mathrm{o}$ : Mean \pm std. dev. $=0.60 \pm 0.24 ; 8 \mathrm{y} / \mathrm{o}$ : Mean \pm std. dev. $=0.35 \pm 0.11 ; 10$ y/o: Mean \pm std. dev. $=0.32 \pm 0.04)$. Regression results show that the differences between $6 \mathrm{y} / \mathrm{o}$ children and the other two age groups are statistically significant $(8 \mathrm{y} / \mathrm{o}-6 \mathrm{y} / \mathrm{o}: \mathrm{B}=-0.25$, robust $\mathrm{SE}=0.061, \mathrm{t}=-4.04, \mathrm{p}<0.001,95 \% \mathrm{CI}=[-0.369,-0.125] ; 10 \mathrm{y} / \mathrm{o}-6 \mathrm{y} / \mathrm{o}: \mathrm{B}=-0.28$, robust $\mathrm{SE}$ $=0.057, \mathrm{t}=-4.89, \mathrm{p}<0.001,95 \% \mathrm{CI}=[-0.391,-0.164])$, whereas there is no difference between 8 and 10 years old participants $(10 \mathrm{y} / \mathrm{o}-8 \mathrm{y} / \mathrm{o}: \mathrm{B}=-0.03$, robust $\mathrm{SE}=0.026, \mathrm{t}=-1.16, \mathrm{p}=0.252,95 \% \mathrm{CI}=[-$ $0.083,-0.022])$.

\section{Effect of age group on final decision, controlling for estimation error}

We added a new control variable to model (1) to adjust for the variability captured by participant's estimation error. This trial-by-trial measure has been computed has the distance between the participant's response and the correct response $(\mathrm{cm})$ divided by the current stimulus length $(\mathrm{cm})$. We used the following mixed-effect logistic model: 


$$
F=\beta_{0}+\beta_{1} a g e+\beta_{2} e+u_{0}+\varepsilon
$$

$F$ is the participant's final binary decision $(1=$ own estimate, $0=$ partner's estimate $)$, age is a dummy variable corresponding to the three age groups $(6,8$ and $10 \mathrm{y} / \mathrm{o})$ and $e$ refers to normalized estimation error. Number of observations $=1240 ;$ number of clusters $=62$.

Results indicate that the age effect of model (1) do not change when adjusting for this control variable, as in model (2). 10 years old children were more influenced by the adult partner than 6 years old ( 6 y/o - 10 $\mathrm{y} / \mathrm{o}: \mathrm{B}=1.09$, robust $\mathrm{SE}=0.261, \mathrm{z}=4.20, \mathrm{p}<.001,95 \% \mathrm{CI}=[0.584,1.605])$ and 8 years old children $(8$ $\mathrm{y} / \mathrm{o}-10 \mathrm{y} / \mathrm{o}: \mathrm{B}=0.64$, robust $\mathrm{SE}=0.206, \mathrm{z}=3.10, \mathrm{p}=.002,95 \% \mathrm{CI}=[0.234,1.042])$. The difference between 6 and 8 years old children is not significant (linear combination of coefficients, 6 y/o -8 y/o: $\mathrm{B}=$ 0.46 , robust $\mathrm{SE}=0.278, \mathrm{z}=1.64, \mathrm{p}=.101,95 \% \mathrm{CI}=[-0.088,1.001])$.

The effect of normalized error on final decision is not significant $(B=-0.06$, robust $\mathrm{SE}=0.183, \mathrm{z}=-0.35$, $\mathrm{p}=.726,95 \% \mathrm{CI}=[-0.422,0.294])$.

We also tested whether between-subject variability in mean normalized estimation error predicts betweensubject heterogeneity in influence (proportion of final decision towards the estimate of the adult partner), within each age group. We did not found any correlation between the two variables in none of the three age groups $(6$ y/o: Spearman correlation, rho $=-0.04, p=0.859 ; 8$ y/o: Spearman correlation, rho $=0.19, \mathrm{p}=$ $0.409 ; 10 \mathrm{y} / \mathrm{o}$ : Spearman correlation, rho $=-0.14, \mathrm{p}=0.522$ ). These results confirm that, at every age level, the general participant's susceptibility to the partner's opinion was not significantly influences by the individual perceptual error. However, we acknowledge that $6 \mathrm{y} / \mathrm{o}$ children show a higher average estimation error compared to the other two age groups $(6 \mathrm{y} / \mathrm{o}$ : Mean \pm std. dev. $=0.62 \pm 0.29 ; 8 \mathrm{y} / \mathrm{o}$ : Mean \pm std. dev. $=0.26 \pm 0.13 ; 10 \mathrm{y} / \mathrm{o}$ : Mean \pm std. dev. $=0.22 \pm 0.06)$. Regression results show that the differences between $6 \mathrm{y} / \mathrm{o}$ children and the other two age groups are statistically significant ( $8 \mathrm{y} / \mathrm{o}-6 \mathrm{y} / \mathrm{o}: \mathrm{B}=-0.29$, robust $\mathrm{SE}$ $=0.066, \mathrm{t}=-4.42, \mathrm{p}<0.001,95 \% \mathrm{CI}=[-0.424,-0.160] ; 10 \mathrm{y} / \mathrm{o}-6 \mathrm{y} / \mathrm{o}: \mathrm{B}=0.33$, robust $\mathrm{SE}=0.061, \mathrm{t}=$ $-5.49, \mathrm{p}<0.001,95 \% \mathrm{CI}=[-0.455,-0.212])$, whereas there is no difference between 8 and 10 years old participants $(10 \mathrm{y} / \mathrm{o}-8 \mathrm{y} / \mathrm{o}: \mathrm{B}=-0.042$, robust $\mathrm{SE}=0.032, \mathrm{t}=-1.32, \mathrm{p}=0.192,95 \% \mathrm{CI}=[-0.105$, $0.021])$.

\section{Learning effects depending on age group}

We explored potential age-dependent learning effects along the experiment. We divided the experimental task in 4 blocks of 10 trials each to investigate the temporal evolution of participants' estimation error. We considered all trials, independently of the experimental condition and turn type. We estimated the following mixed-effect logistic model: 


$$
E=\beta_{0}+\beta_{1} b+\beta_{2} a g e+\beta_{3} b * a g e+u_{0}+\varepsilon
$$

$E$ is the trial-by-trial participant's normalized estimation error, $b$ is the experimental block (1-4) and age is a dummy variable for participants' age group. Number of observations $=2480$; number of clusters $=62$.

Results did not reveal any effect of block or interaction between age and block (contrasts of marginal linear predictions, block: $\mathrm{df}=3$, chi $2=1.44, \mathrm{p}=0.696$; group*block: $\mathrm{df}=6$, chi2 $=3.09, \mathrm{p}=0.797$ ). We also found a significant effect of age (contrasts of marginal linear predictions, group: $\mathrm{df}=2$, chi2 $=31.86, \mathrm{p}<$ 0.001), reflecting the decrease of estimation error along with age that we have already observed in previous analyses reported in the main manuscript. In particular, we observe that the estimation error of 6 y/o children is significantly higher than the other two groups $(8 \mathrm{y} / \mathrm{o}-6 \mathrm{y} / \mathrm{o}: \mathrm{B}=-0.29, \mathrm{t}=-4.42, \mathrm{p}<0.001 ; 10 \mathrm{y} / \mathrm{o}-6$ $\mathrm{y} / \mathrm{o}: \mathrm{B}=0.33, \mathrm{t}=-5.49, \mathrm{p}<0.001$ ), whereas there is no difference between 8 and 10 years old participants $(10 \mathrm{y} / \mathrm{o}-8 \mathrm{y} / \mathrm{o}: \mathrm{B}=-0.042, \mathrm{t}=-1.32, \mathrm{p}=0.192)$.

\section{Effect of agents' response distance on final decision depending on age group}

We tested the effect of trial-by-trial agents' response distance on participants' final decision in decision turns, depending on participants' age group. In this analysis, we considered all decision trials, independently of the experimental condition. We estimated the following mixed-effect logistic model:

$$
F=\beta_{0}+\beta_{1} d+\beta_{2} \text { age }+\beta_{3} d * a g e+u_{0}+\varepsilon
$$

$F$ is the participant's final binary decision ( $1=$ own estimate, $0=$ partner's estimate $), d$ is the normalized distance between the two agents 'responses and age is a dummy variable corresponding to the three age groups $(6,8$ and $10 \mathrm{y} / \mathrm{o})$. Number of observations $=1240$; number of clusters $=62$.

Results show that 10 years old children modulated influence in function of the current agents' response distance $(\mathrm{B}=0.99$, robust $\mathrm{SE}=0.458, \mathrm{z}=2.17, \mathrm{p}=.030,95 \% \mathrm{CI}=[0.097,1.891])$, with higher distances leading to a lower probability to follow the partner's advice. Conversely, younger children did not show any relationship between distance and influence $(6 \mathrm{y} / \mathrm{o}: \mathrm{B}=0.04$, robust $\mathrm{SE}=0.246, \mathrm{z}=0.17, \mathrm{p}=.0 .863$, $95 \% \mathrm{CI}=[-0.439,0.524] ; 8 \mathrm{y} / \mathrm{o}: \mathrm{B}=0.27$, robust $\mathrm{SE}=0.365, \mathrm{z}=0.73, \mathrm{p}=.464,95 \% \mathrm{CI}=[0.448,0.981])$.

\section{Reciprocity}

\section{Effect of condition on final decision depending on age group}


We tested the effect of age group and experimental condition (Susceptible, Unsusceptible) on participants' final decision in decision turns. We estimated the following mixed-effect logistic model:

$$
F=\beta_{0}+\beta_{1} c+\beta_{2} a g e+\beta_{3} c * a g e+u_{0}+\varepsilon
$$

$F$ is the participant's final binary decision $(1=$ own estimate, $0=$ partner's estimate $), c$ is the current experimental condition (Susceptible, Unsusceptible) and age is a dummy variable corresponding to the three age groups $(6,8$ and $10 \mathrm{y} / \mathrm{o})$. Number of observations $=1240$; number of clusters $=62$.

Results show a significant effect of condition in 10 years old children (unsusc. - susc.: $B=0.31$, robust SE $=0.109, \mathrm{z}=2.86, \mathrm{p}=.004,95 \% \mathrm{CI}=[0.098,0.526])$. These children switched opinion towards the one of the adult partner more often when the latter had previously shown high consideration towards them. This effect was absent in younger children $(6 \mathrm{y} / \mathrm{o}: \mathrm{B}=0.15$, robust $\mathrm{SE}=0.215, \mathrm{z}=0.69, \mathrm{p}=.0 .489,95 \% \mathrm{CI}=$ $[-0.273,0.571] ; 8 \mathrm{y} / \mathrm{o}: \mathrm{B}=0.22$, robust $\mathrm{SE}=0.220, \mathrm{z}=1.18, \mathrm{p}=.0 .239,95 \% \mathrm{CI}=[-0.146,0.587])$.

\section{Effect of condition on final decision depending on age group, controlling for agents' response distance}

First, it is important to highlight that there were no difference in terms of average normalized distance between conditions in none of the three age groups (Wilcoxon signed-rank test, $6 \mathrm{y} / \mathrm{o}: \mathrm{z}=0.41, \mathrm{r}=0.07, \eta^{2}$ $=0.00, \mathrm{p}=0.679 ; 8$ y/o: $\mathrm{z}=-1.23, \mathrm{r}=0.19, \eta^{2}=0.04, \mathrm{p}=0.217 ; 10 \mathrm{y} / \mathrm{o}: \mathrm{z}=-0.33, \mathrm{r}=0.05, \eta^{2}=0.00, \mathrm{p}$ $=0.738)$.

We then added a control variable to the previous model (6) to adjust for the variability captured by trial-bytrial agents' response distance. We used the following mixed-effect logistic model:

$$
F=\beta_{0}+\beta_{1} c+\beta_{2} a g e+\beta_{3} c * a g e+\beta_{4} d+u_{0}+\varepsilon
$$

$F$ is the participant's final binary decision ( $1=$ own estimate, $0=$ partner's estimate), $c$ expresses the current experimental condition (Susceptible, Unsusceptible), age is a dummy variable corresponding to the three age groups $(6,8$ and $10 \mathrm{y} / \mathrm{o})$, and $d$ refers to normalized agents' response distance. Number of observations $=1240$; number of clusters $=62$.

Results indicate that the effects of condition found in model (6) do not change when adjusting for normalized agents' response distance. In particular, we found a significant effect of condition in 10 years old children (unsusc. - susc.: $\mathrm{B}=0.31$, robust $\mathrm{SE}=0.109, \mathrm{z}=2.84, \mathrm{p}=.005,95 \% \mathrm{CI}=[0.096,0.523]$. This effect is not present in younger participants $(6 \mathrm{y} / \mathrm{o}: \mathrm{B}=0.16$, robust $\mathrm{SE}=0.216, \mathrm{z}=0.76, \mathrm{p}=.0 .449$, $95 \% \mathrm{CI}=[-0.260,0.588] ; 8 \mathrm{y} / \mathrm{o}: \mathrm{B}=0.21$, robust $\mathrm{SE}=0.187, \mathrm{z}=1.14, \mathrm{p}=.0 .255,95 \% \mathrm{CI}=[-0.153$, 
0.578]). The effect of agents' response distance is not significant $(B=0.21$, robust $\mathrm{SE}=0.207, \mathrm{z}=1.01, \mathrm{p}$ $=.0 .311,95 \% \mathrm{CI}=[-0.196,0.615])$.

Effect of condition on final decision depending on age group, controlling for participants' estimation error

First, it is important to highlight that there were no difference in terms of participants' perceptual error (normalized by stimulus length) between conditions in none of the three age groups (Wilcoxon signed-rank test, 6 y/o: $\mathrm{z}=0.33, \mathrm{r}=0.05, \eta^{2}=0.00, \mathrm{p}=0.744 ; 8 \mathrm{y} / \mathrm{o}: \mathrm{z}=-1.75, \mathrm{r}=0.27, \eta^{2}=0.07, \mathrm{p}=0.079 ; 10 \mathrm{y} / \mathrm{o}$ : $\left.\mathrm{z}=-0.33, \mathrm{r}=0.05, \eta^{2}=0.00, \mathrm{p}=0.903\right)$.

We then added a new control variable to model (5) to adjust for the variability captured by trial-by-trial normalized estimation error. We used the following mixed-effect logistic model:

$$
F=\beta_{0}+\beta_{1} c+\beta_{2} a g e+\beta_{3} c * a g e+\beta_{4} e+u_{0}+\varepsilon
$$

$F$ is the participant's final binary decision ( $1=$ own estimate, $0=$ partner's estimate), $c$ expresses the current experimental condition (Susceptible, Unsusceptible), age is a dummy variable corresponding to the three age groups $(6,8$ and $10 \mathrm{y} / \mathrm{o})$, and $e$ refers to participants' normalized estimation error. Number of observations $=1240 ;$ number of clusters $=62$.

Results indicate that the effects of condition found in model (6) do not change when adjusting for participants' perceptual error. In particular, we found a significant effect of condition in 10 years old children (unsusc. - susc.: $\mathrm{B}=0.31$, robust $\mathrm{SE}=0.109, \mathrm{z}=2.86, \mathrm{p}=.004,95 \% \mathrm{CI}=[0.098,0.526]$. This effect is not present in younger participants $(6 \mathrm{y} / \mathrm{o}: \mathrm{B}=0.15$, robust $\mathrm{SE}=0.216, \mathrm{z}=0.67, \mathrm{p}=.0 .500,95 \%$ $\mathrm{CI}=[-0.278,0.569] ; 8 \mathrm{y} / \mathrm{o}: \mathrm{B}=0.22$, robust $\mathrm{SE}=0.188, \mathrm{z}=1.19, \mathrm{p}=.0 .234,95 \% \mathrm{CI}=[-0.145,0.591]$. The effect of estimation error is not significant $(B=-0.07$, robust $\mathrm{SE}=0.182, \mathrm{z}=-0.37, \mathrm{p}=.0 .711,95 \%$ $\mathrm{CI}=[-0.424,0.289])$. 